\title{
A systematic review of Security and Privacy issues in the Internet of Medical Things; The role of Machine Learning approaches
}

\author{
Shilan S. Hameed ${ }^{\text {Corresp., } 1,2}{ }^{\text {, Wan H Hassan }}{ }^{1}$, Liza Abdul Latiff ${ }^{3}$, Fahad Ghabban ${ }^{4}$ \\ 1 Malaysia-Japan International Institute of Technology (MJIIT), Universiti Teknologi Malaysia, Kuala Lumpur, Malaysia \\ 2 Directorate of Information Technology, Koya University, Koya, Kurdistan Region, Iraq \\ 3 Razak Faculty of Technology and Informatics, Universiti Teknologi Malaysia, Kuala Lumpur, Malaysia \\ 4 Information Systems Department, College of Computer Sciences and Engineering, Taibah University, Medina, Saudi Arabia, Saudi Arabia \\ Corresponding Author: Shilan S. Hameed \\ Email address: hameed.s@graduate.utm.my
}

Background . The Internet of Medical Things (IoMTs) is gradually replacing the traditional healthcare system. However, little attention has been paid to their security requirements in the development of the IoMT devices and systems. One of the main reasons can be the difficulty of tuning conventional security solutions to the loMT system. Machine Learning (ML) has been successfully employed in the attack detection and mitigation process. Advanced ML technique can also be a promising approach to address the existing and anticipated loMT security and privacy issues. However, because of the existing challenges of IoMT system, it is imperative to know how these techniques can be effectively utilized to meet the security and privacy requirements without affecting the loMT systems quality, services, and device's lifespan.

Methodology. This paper is devoted to perform a Systematic Literature Review (SLR) on the security and privacy issues of IoMT and their solutions by ML techniques. The recent research papers disseminated between 2010 to 2020 are selected from multiple databases and a standardized SLR method is conducted. A total of 153 papers were reviewed and a critical analysis were conducted on the selected papers. Furthermore, this review study attempts to highlight the limitation of the current methods and aims to find possible solutions to them. Thus, a detailed analysis was carried out on the selected papers through focusing on their methods, advantages, limitations, the utilized tools, and data.

Results. It was observed that ML techniques have been significantly deployed for device and network layer security. Most of the current studies improved traditional metrics while ignored performance complexity metrics in their evaluations. Their studies environments and utilized data barely represent IoMT system. Therefore, conventional ML techniques may fail if metrics such as resource complexity and power usage are not considered. 
1 A systematic review of Security and Privacy issues in the Internet of Medical Things; The role of Machine Learning approaches

4

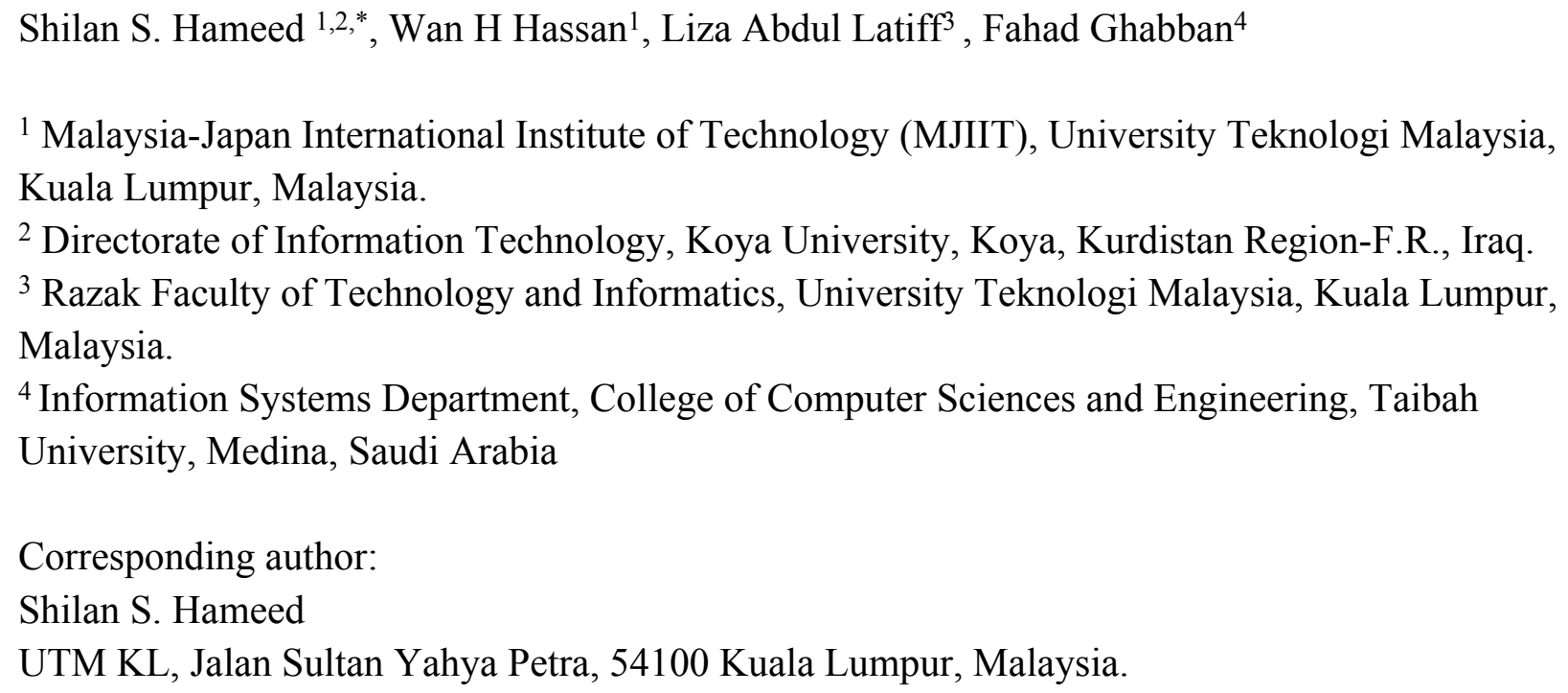

\section{Abstract}

Background. The Internet of Medical Things (IoMTs) is gradually replacing the traditional healthcare system. However, little attention has been paid to their security requirements in the development of the IoMT devices and systems. One of the main reasons can be the difficulty of tuning conventional security solutions to the IoMT system. Machine Learning (ML) has been successfully employed in the attack detection and mitigation process. Advanced ML technique can also be a promising approach to address the existing and anticipated IoMT security and privacy issues. However, because of the existing challenges of IoMT system, it is imperative to know how these techniques can be effectively utilized to meet the security and privacy requirements without affecting the IoMT systems quality, services, and device's lifespan. Methodology. This paper is devoted to perform a Systematic Literature Review (SLR) on the security and privacy issues of IoMT and their solutions by ML techniques. The recent research papers disseminated between 2010 to 2020 are selected from multiple databases and a standardized SLR method is conducted. A total of 153 papers were reviewed and a critical analysis were conducted on the selected papers. Furthermore, this review study attempts to highlight the limitation of the current methods and aims to find possible solutions to them. Thus, a detailed analysis was carried out on the selected papers through focusing on their methods, advantages, limitations, the utilized tools, and data. 
Results. It was observed that ML techniques have been significantly deployed for device and network layer security. Most of the current studies improved traditional metrics while ignored performance complexity metrics in their evaluations. Their studies environments and utilized data barely represent IoMT system. Therefore, conventional ML techniques may fail if metrics such as resource complexity and power usage are not considered.

Keywords: The Internet of Medical Things, IoMT, Security and Privacy, Machine Learning

\section{Background}

\section{A. IoMT and its Classification}

The Internet of Thing (IoT) is a fast growing technology by which the infrastructures, computerized machines, physical things, applications and individuals are allowed to connect, communicate, capture and exchange information through networking (Farahani et al. 2018; Noor \& Hassan 2019). Hence, the Internet of Medical Thing (IoMT) is the application of IoT in medicine and healthcare industry (Alsubaei et al. 2019a; He et al. 2018). It is anticipated that with the implementation of IoMT a significant improvement in the efficiency and standard of treatment is achieved thanks to the steady innovations in IoT including the development in microprocessors, biosensor architecture and evolving 5G technologies (Ahad et al. 2019). However, it is hard to maintain a specific architecture as a baseline due to the variety of devices and their different usage. Consequently, various approaches for the IoT architectures and layers were presented in literature (Sethi \& Sarangi 2017; Weyrich \& Ebert 2015) such as protocolbased architecture (Burhan et al. 2018; Mosenia \& Jha 2016; Weyrich \& Ebert 2015) and data processing stages known as edge, fog, and cloud based approaches (Escamilla-Ambrosio et al. 2018). In the current review, we present two common architectures of the IoMT. In the first architecture, the IoMT is treated as to be composed of three main elements: (i) network of wireless body sensor, which is device layer, (ii) internet connected smart access points (gateway), which is fog layer, and (iii) cloud computing and big data service, which is cloud layer (Rahmani et al. 2018). The second architecture is simply defined by sensing/device layer, network layer, and server (personal/medical) layer (Sun et al. 2019). However, some researchers have divided the IoMT architecture into more than three layers based on the requirements adopted for a specific application of IoMT (Elrawy et al. 2018; Grammatikis et al. 2019). Furthermore, there are four types of smart medical devices in IoMT that are categorized based on their location of implementation on human body (Nanayakkara et al. 2019). Table 1 shows a brief explanation on the types of IoMT devices and their properties. According to the U.S. Food and Drug Administration (FDA), the IoMT devices can be also classified based on their risk value. Implantable devices such as Implantable cardioverter-defibrillator (ICD), Electrocardiography (ECG), Electromyography (EMG), and Electroencephalography (EEG) are under high-risk category. Hence, they are regulated and certified by FDA. However, nonimplantable devices such as fitness trackers, and smart watches are under low-risk category. Therefore, they neither require certification nor regulation by the FDA (Jaigirdar et al. 2019).

\section{Table 1:}


80

81

82

\section{The types and characteristics of medical devices used in the IoMT system.}

Medical devices and biosensors are responsible for capturing body's vital signs, and transferring a huge real-time raw biological data such as heart rate, brain signal, temperature of the body, and glucose level in blood (Dang et al. 2019). These raw data are accumulated and processed at the personal servers that are either devices located near the patient's body such as mobile phones, medical programmers, and laptops or devices placed far from body such as gateways and routers. Additionally, personal servers usually include a computing analysis facility, which is coupled with a local archiving database in order to store the initial records of the patient. Furthermore, its warning system alerts the patient whenever an abnormality is observed (Newaz et al. 2020). The communication link between body area network (sensors attached to or close to human body) and personal server is usually employed by low-power wireless networking technologies such as Bluetooth or Bluetooth Low Energy (BLE), Near-Field Communication (NFC), RadioFrequency IDentification (RFID), Zigbee and Z-Wave. Noteworthy, Bluetooth is mostly used in wearable devices, while RFID and NFC are accommodating an ultra-low energy and short-range communication topology. Hence, they are mostly applicable in the implantable devices (Newaz et al. 2020; Sun et al. 2019). In this way, the aggregated data at the personal server is directed to the medical server. Long-range wireless technologies such as Wi-Fi, GSM and LoRa are also used for the connection between the personal server gateway and medical sever.

The data analytics are conventionally performed at the cloud. However, cloud computing faces the issues of delay and privacy. For this reason, the term of fog computing at gateways (fog devices) was introduced in 2017 (Rahmani et al. 2018). This approach is used to shift some of the cloud computing works closer to the smart devices aiming at achieving a faster computation with keeping privacy (Dang et al. 2019; Firouzi et al. 2018; Rahmani et al. 2018). It is not deniable that using smart medical devices has made the life easier and healthier. However, there are many safety and security gaps in these devices that put not only the devices at risk but expose a significant risk to the patient's life (Yaacoub et al. 2020)

\section{B. Security and Privacy in the loMT}

The IoMT devices are vulnerable to traditional and zero-day attacks. This is mainly due to the lack of existing security protocols and measures in the fabrication of the devices in addition to the nature of the devices and IoT network. The devices are very tiny, where their computational resources and batteries cannot handle computation of cryptographic and existing heavy security measures. Furthermore, the network of IoMT is heterogeneous, which is composed of different protocols at each layer, making one security solution not applicable to all devices. It was reported in an estimation made by the Statista (The Statistics Portal) that the number of medical IoT devices in the European Union (EU) could reach 25.8 million devices by 2025 (Schneble \& Thamilarasu 2019b). In addition to a steady increase in the number of smart medical devices and benefits from the low price of wireless sensors, the security and privacy issues are become the main concern (He et al. 2018). Besides, when internet connected devices are increased, their 
120 produced data will eventually increase (Dimitrov 2016; Firouzi et al. 2018; Ma et al. 2017). It 121 was predicted by Statista that IoT devices could produce about 79.4 zettabytes (ZB) by 2025 (S. 122 O'Dea 2020). It is well known that not only the IoMT devices are at risk of cyber-attack, their 123 data are also at a high risk. In fact, privacy issues and data disclosure are the current utmost 124 issues in IoMT infrastructure (Gupta et al. 2020b; Xu et al. 2020)..

125 The IoMT security and privacy requirements are different from the traditional network 126 requirements which are usually referred to as CIA-triad (confidentiality, integrity, and 127 availability). Other metrics such as privacy, and non-repudiation are also essential for the IoMT 128 system (Grammatikis et al. 2019; Nanayakkara et al. 2019; Newaz et al. 2020; Yaacoub et al. 129 2020). The followings are definitions of these metrics used in IoMT system.

130 a) Confidentiality: It limits unauthorized access to certain information and it guarantees the 131 protection of confidential information. Unauthorized access may lead to data leakage and sometimes life-threatening situations (Alassaf \& Gutub 2019).

b) Integrity: It ensures that the data and reading of devices are not altered, deleted, or injected by unauthorized parties. Attacks on integrity such as false data injection on implantable pacemaker may lead to death (Yaacoub et al. 2020).

c) Availability: It ensures that the data, computing elements, and communications are accessible and working continuously when they are required by a service. System service interruption poses danger on patients health, considering a surgery room equipped with wireless medical devices (Sun et al. 2019).

d) Privacy: It ensures that privacy rules are enforced by the IoMT system and allows users to access their private details (Mosenia \& Jha 2016). The collection of confidential health records must conform with legal and ethical laws of privacy such as the General Data Protection Regulation (GDPR) and the Health Insurance Portability and Accountability Act (HIPAA) (Gupta et al. 2020b; Tovino 2016). These rules ensure the protection of private patient data from disclosure. It is important that Electronic Health Records (EHRs) should not be kept beyond the time of their need. Data should not be breached while stored, transmitted, and used (Hassija et al. 2019). Due to open communication channels and neglecting data privacy, the possibility of confidential and private details being released, hacked, or compromised is extremely high. This can be compromised through passive attacks or active attacks (Yaacoub et al. 2020).

e) Non-repudiation: This metric encompasses the ability of the system to validate the presence or absence of an activity (Mosenia \& Jha 2016; Yeh 2016). It ensures that the sending node is granted a delivery receipt and the receiver node is granted a proof on the identity of the sender so that none of them is denied in the process (Newaz et al. 2020). A threat that risks any of the aforementioned pillars of IoMT security and privacy is considered an attack. Table 2 shows the categorized attacks based on the IoMT targeted layer with respect to their impacts on the security requirements of IoMT system. It is worth to mention that despite of the reported attacks the appearance of zero-day attacks is a daily possibility. While these attacks are threatening the privacy of patients, it is also resulted in unbearable financial damage and loss of reputation (Sun et al. 2019). For example, a recent ransomware attack on hospitals in the 
160 USA, which infected 400 U.S. sites has resulted in service disruption and data disclosure (Davis

161

162

163

164

165

166

167

168

169

170

171

172

173

174

175

176

177

178

179

180

181

182

183

184

185

186

187

188

189

190

191

192

193

194

195

196

197

198

199

2020b). According to a latest analysis by Comparitech, these attacks have cost the healthcare industry over $\$ 160$ million since 2016 (Davis 2020a). Additionally, it was claimed that attacks on brain implants, lead to death (Rathore et al. 2019). Therefore, with the increased risk of cyberattack on the IoMT system, the emergence and development of robust security solutions are become a must.

\section{Table 2:}

Attacks on different IoMT layers with their respective impact on security requirements.

\section{Machine Learning Techniques and their Evaluation Metrics}

Machine Learning (ML) is a branch of Artificial Intelligence (AI) which learns from data and experiences without being explicitly programmed (Kubat 2017). ML can play a vital role in IoMT, especially at computing nodes such as cloud/fog computing, for continuous data analysis and producing meaningful information. Recently, ML has been interestingly applied in various areas of IoT and IoMT (Alimadadi et al. 2020; Ardabili et al. 2020; Cui et al. 2018; Durga et al. 2019; Pannu 2015; Pramanik et al. 2017; Xiao et al. 2018). ML can be effectively used in many ways to tackle the security issues of the IoMT (Cui et al. 2018; Gupta et al. 2020a; Pandey et al. 2020; Pirbhulal et al. 2019), whereas traditional security measures cannot prevent the system from zero-day attacks, and they are resource extensive for the IoMT systems. Advanced ML techniques can learn from massive generated data of IoMT, thereby finding new trends of attacks (Hussain et al. 2020). Hence, data hungry ML techniques can be perfectly tuned with IoMT. There are three main types of ML algorithms which can be used for solving the IoMT security problems, namely supervised, unsupervised, and semi-supervised algorithms. The Supervised technique deals with labelled data, in which classes or labels are known. There are two forms of supervised learning which are classification and regression (Kubat 2017). Examples of supervised learning are Support Vector Machine, Decision Trees and Neural Network. These methods are used for the attack and malware detection purpose such as signature based Intrusion Detection System (IDS) (Eskandari et al. 2020; RM et al. 2020). Since it is not always easy to label the data by human, unsupervised techniques are utilized to categorize them based on their similar traits (Schneble \& Thamilarasu 2019b). Examples of these techniques are Knearest Neighbor (KNN), Self-Organizing Map (SOM), and Latent Dirichlet Allocation (LDA) (Gupta et al. 2020a). These methods are effective for anomaly detection of new attacks (Ahmad et al. 2019; Bostani \& Sheikhan 2017; Eskandari et al. 2020). Based on the no free lunch theory, not every unlabeled data is useful for prediction (Rathore \& Park 2018). Hence, one can overcome this issue by incorporating some labelled data. Semi-Supervised Learning is a younger ML sub-field, in which some data are labelled out of a wide number of learning data (Wolfgang 2011). Also, semi-supervised models can be used for attack detection and to avoid adversarial attacks on ML techniques (Miyato et al. 2018; Rathore \& Park 2018). In addition to the main classes of ML, a new branch called Deep learning $(D L)$ has been recently emerged,

Peer) Comput. Sci. reviewing PDF | (CS-2020:10:53665:1:1:NEW 19 Jan 2021) 
200

201

202

203

204

205

206

207

208

209

210

211

212

213

214

215

216

217

218

219

220

221

222

223

224

225

226

227

228

229

230

231

232

233

234

235

236

237

238

which is an advanced form of Neural Network. It has several layers of artificial neural network that mimic the working principle of human brain in processing data for detecting objects, recognizing speech, translating languages, and making decisions. DL can perform feature selection/extraction based on its learning process without the need of another method compared to traditional ML techniques that require an additional feature selection (Amanullah et al. 2020). DL comes in different forms, including Convolution Neural Network (CNN), Recurrent Neural Network (RNN), Long-Short Term Memory (LSTM), Auto-Encoders (AE), Boltzmann Machine (BM), Generative Adversarial Networks (GAN), Feed forward Deep Networks (FDN) and Deep Belief Networks (DBN) (Amanullah et al. 2020; Hussain et al. 2020; Saeed et al. 2016). Autoencoders are usually the best choice of unsupervised learning to be used for anomaly detection (Lopez-Martin et al. 2017). The use of DL for security solutions such as attack detection could be a durable method for slight mutations or new threats due to its ability to extract features (Amanullah et al. 2020; Diro \& Chilamkurti 2018; Durga et al. 2019; Ibitoye et al. 2019; Parra et al. 2020; Sollins 2018). On the other hand, the IoMT sensors generate a large amount of data at a fast speed, thereby producing Big data (Cao 2017; Pramanik et al. 2017; Saheb \& Izadi 2019) (Marjani et al. 2017). Big data refers to the data that are too large and/or complex to be efficiently handled by conventional technologies and tools (Dimitrov 2016; Hameed et al. 2017; Sadoughi et al. 2020; Vinitha et al. 2018). A big data is usually defined by three key features, known as $3 \mathrm{Vs}$, which are volume, velocity and variety (Amanullah et al. 2020; Russom 2011). It was seen in literature that DL and big data have been used together as DL performs better with increasing the amount of data (Gheisari et al. 2017). Very recently, DL and Big Data were used in combination with new technologies of blockchain and reinforcement learning for security purposes in the industrial IoT systems (Aman et al. 2020; Liang et al. 2020; Liu et al. 2018). Concludingly, the ML methods can be employed in different security solutions such as:

Sensor Anomaly Detection in Medical Devices: Anomaly detection is the process of finding deviations from the normal data. Such anomalies are attributed to the occurrence of phenomena that do not obey a regular process. These irregularities are triggered by abnormal behaviors such as internal assault or false data injection attack (Amanullah et al. 2020), leading to a false reading of the sensors. ML approach in anomaly detection is the most used mechanism for sensor security. Nonetheless, it needs a considerable adoption in order to be implemented in the IoMT (Butun et al. 2015; Hasan et al. 2019).

Authentication and Access Control: Authentication is the process of ensuring whether the IoMT user is correct, while authorization is associated with the extent of access given to each individual (patient and healthcare provider)(Aghili et al. 2019b). They are the most effective methods to prevent attacks on confidentiality and integrity of the IoMT data (Aghili et al. 2019b; Nguyen et al. 2019; Yang et al. 2018). Different techniques can be combined in the process of authentication and authorization such as cryptography, ML, and lightweight approaches (Aghili et al. 2019b; Shen et al. 2018; Wu et al. 2018). Details about these methods can be found in (Sun et al. 2019). 
239

240

241

242

243

244

245

246

247

248

249

250

251

252

253

254

255

256

257

258

259

260

261

262

263

264

265

266

267

268

269

270

271

272

273

274

275

276

277

278

Intrusion and Malware Detection: The most common intrusion detection is network intrusion detection (NIDS) using network traffic analysis. If the log data of sensors and devices are used, it becomes host-based intrusion detection (HIDS) (Aluvalu 2020). Both types of intrusion detection use metrics for finding anomalies (unknown-attacks) and signatures (known-attacks) that do not match with the normal network traffic or sensor data. These detection systems are similar in having an agent for collecting data and a processing unit in the attack detection and reporting the intrusions. However, they are different in: i) Source of data: host-based (Asfaw et al. 2010), network-based (Maleh et al. 2015), hybrid (Ahmad et al. 2019), ii) Method of detection (Abhishek et al. 2018): signature-based (Wang et al. 2018), anomaly-based, and iii) Architecture: centralized, and distributed (Anthi et al. 2018; da Costa et al. 2019). Signature based approaches can easily detect the known attacks but unable to detect new attacks. On the other hand, anomaly-based IDS find anomalous behavior by learning from current data. Therefore, they can detect new attacks, but they are less accurate and computationally expensive (Arshad et al. 2020; Jan et al. 2019; Midi et al. 2017). The recent attacks such as DoS, DDoS and different malware attacks are the most common mitigated attacks by IDSs (Din et al. 2019; Meidan et al. 2018; Roopak et al. 2020).

In the process of evaluating ML techniques in terms of accuracy, reliability, and applicability, some special metrics should be considered. Table 3 shows the most used metrics with their definition and formula.

\section{Table 3:}

\section{The evaluation metrics used for ML techniques.}

\section{IoMT Security and Privacy Solutions using Machine Learning.}

\section{Research Rationale}

The unique nature of the IoMT system with small size devices, heterogeneous network, and diverse protocols, has made the implementation of traditional security frameworks difficult by the medical companies. This in turn makes the IoMT system suspectable to different attacks. Recent advancement in the techniques and technologies of ML has led to achieve fruitful strategies to tackle the issues of IoMT security. However, IoMT system facing more challenges than ordinary network systems.

IoMT devices usually generate a large amount of streaming data (Amanullah et al. 2020). The diversity nature of these data along with the limited power and resources of IoMT devices, especially for the implantable medical devices (Sun et al. 2019), impose a high computational burden on the traditional ML techniques, thereby reducing their effective application in the IoMT devices. Hence, new strategies are required to apply the ML approaches efficiently.

Consequently, understanding the current security and privacy issues of IoMT system with their respective solutions using ML techniques is essential. Furthermore, it is significant to know the effectiveness of current deployed ML techniques and to understand their solution strength 
279

280

281

282

283

284

285

286

287

288

289

290

291

292

293

294

295

296

297

298

299

300

301

302

303

304

305

306

307

308

309

310

311

312

313

314

315

316

317

318

offered to the challenges of IoMT system so far. We found that little attention has been paid in literature to elaborate on these issues. Therefore, in this work, a Systematic Literature Review (SLR) is presented, in which attempts are made to reveal the strong points and limitations of the works performed in this area followed by establishing robust improvement strategies. As such, three research questions can be generated as follows:

RQ1: What is the current state of the art and direction of study in IoMT security using ML? RQ2: What kind of tools and data are used for applying ML techniques in IoMT security? RQ3: How ML techniques are effectively applied and what are their limitations?

This study is intended for new researchers in the field, and for those who are keen to know about recent advances and limitations in IoMT security issues followed by their solutions using ML approaches.

\section{Related Studies}

In a review performed by Cui et al. (Cui et al. 2018), an overview of ML application in the domain of generic IoT was reported to focus on the main applications of ML and its relevant techniques in IoT. However, the work has partially covered the IoT security solutions with ML. In another study (Tahsien et al. 2020), Tahsien et al. reviewed the architectures of generic IoT and ML-based potential solutions for IoT security. Another comprehensive review on using ML techniques in generic IoT security was also conducted by Hussain et al. (Hussain et al. 2020). The authors discussed major threats to each layer of IoT and reviewed recent works of using ML techniques in securing IoT. Noticeably, the reviewed studies, tools and datasets were not comprehensively elaborated and the IoMT system was not explored. A review study on security and privacy of IoMT was conducted by Sun et al., revealing the security requirements and challenges of IoMT with more focus on authentication and access control (Sun et al. 2019). Moreover, a survey on IoMT security and privacy was carried out by Newaz et al (Newaz et al. 2020), in which a detailed discussion was given on the security and privacy threats in healthcare systems. They also presented a subsection on the current solutions for healthcare IoT security. On the other hand, a review on IoMT security issues and limitations with details about the attacks and their impact on IoMT was presented, whereas a special attention was paid on lightweight security solutions (Yaacoub et al. 2020). Concludingly, there have been some reviews found in literature about generic IoT security using ML and DL. However, little attention has been paid to ML applications for the IoMT security and privacy. To this end, the current review is intended to address the role of ML technologies in tackling the issues of IoMT security and privacy. That is by carrying out a comprehensive and systematic review on the related works performed in literature. For this reason, it is difficult to compare our work with the existing surveys. However, a fair relevant comparison of the previous reviews with that of the current study is given in Table 4.

\section{Table 4:}

\section{Comparison between this survey and other related surveys.}




\section{Survey methodology}

\section{Research Design}

In the current work, a systematic research design is generated. After creating a list of research questions, searching for relevant papers was started from different databases including IEEE, Web of Science, Springer Link, Scopus, Science Direct. Then, the most specific and relevant papers were extracted to answer the research questions. Later on, the selected papers were comprehensively screened and analyzed. Finally, the results were presented using different methods.

\section{Database Searching and Research Selection}

A keyword-based search was applied by using different forms and combinations of Machine Learning, The Internet of Medical Things, Security and Privacy and their synonyms. Then, the synonym list was expanded during researching and a Research Information Template (RIT) was generated accordingly, as shown in Fig. 1. Boolean expressions with all the keyword combinations were constructed to form all the searching possibilities. The literature searches were carried out in April 2020, whereas each RIT query string was checked in the respective databases followed by saving the query results. The period affecting this analysis was justified between January 2010 and April 2020. Initially, the full metadata would have been selected for searching and if this option was not available, the common search choice (keyword, title and abstract) was used. The search queries and results returned by the databases are shown in Table 5. Noteworthy, a total of 28,155 search results were returned from all the five databases. The titles were then examined for significant and duplicate papers and a total of 500 papers were remained. After that, the papers whose mentioned IoMT/ML/security and privacy were chosen. As such, a total of 153 publications were filtered and the remainder was removed. After going through the full text of the papers, only 43 papers were selected for critical analysis and conducting a careful review of their contents. The rest of the papers were used while discussing the topics related to the background of the study. The selection criteria given in Table 6 were performed equally on the title, abstract, conclusion, and full paper in all stages of screening, while the detailed process of the methodology is shown in Fig. 2.

\section{Table 5:}

The searching queries and results achieved from five different databases.

Table 6:

The selection criteria applied to the reviewed papers.

Figure 1: The keywords used in the Research Information Template (RIT).

Figure 2: The search strategy used for selecting the research papers. 
359

360

361

362

363

364

365

366

367

368

369

370

371

372

373

374

375

376

377

378

379

380

381

382

383

384

385

386

387

388

389

390

391

392

393

394

395

396

397

\section{Results and findings}

In this work, two types of analysis were performed which include a bibliometric analysis and technical analysis, as discussed in the next subsections.

\section{Bibliometric Analysis}

To show the leading countries whose researchers working in the field of IoMT and its security, each individual paper was examined according to the affiliation of authors. It was observed that the USA has made $30 \%$ of the papers among 21 affiliated countries, as shown in Fig. 3.

Moreover, it was found that research performed on ML applications in the IoMT security has grown steadily from 10 percent in 2015 to a peak value of 80 percent in 2019, as shown in Fig. 4.

\section{Figure 3: Geographical distribution of the papers.}

\section{Figure 4: Distribution of the papers by year.}

It is worth to mention that the majority of the papers were journal article, contributing to $73 \%$ of the papers, while $21 \%$ of the papers were from conferences of the Institute of Electrical Electronics Engineering (IEEE) and only 6\% of the papers were belong to book chapters as seen in Fig. 5. Furthermore, a significant number of papers (64\%) was published by the IEEE and 17\% was published by Elsevier, as seen in Fig. 6.

Figure 5: The type of analyzed papers used in the current research.

Figure 6: Distribution of the papers according to the publishers.

\section{Studies Technical Analysis}

\section{Classification of Studies}

The vast majority of ML related articles were about supervised ML, while the rest of papers were found to report on a combination of supervised and unsupervised ML, with few papers to focus on unsupervised ML. Deep learning was also used in some of the studies, while one study has used big data technology. The papers were further categorized based on the type of medical devices intended to get secured. Almost all studies have focused on the security of wearable devices, while few of them elaborated on the security measures for implantable devices. Only one study was found to focus on securing programmer devices. The targeted IoMT layers in most 
398

399

400

401

402

403

404

405

406

407

408

409

410

411

412

413

414

415

416

417

418

419

420

421

422

423

424

425

426

427

428

429

430

431

432

433

434

435

436

437

of the studies were device and sensor layers. Network layer was addressed in some studies, while cloud layer was reported by two paper. Table 7 shows further details on the disseminated studies related to their ML category and types of devices with their targeted layer.

The papers were then classified into different subsections based on the approaches taken to tackle the security issues of the IoMT, as was discussed in the background section. In addition, an in-depth assessment was carried out through a critical analysis of the articles, demonstrating the strong characteristics and limitations of each study. In the following sections, we discuss on the findings of the aforementioned analysis.

\section{Table 7:}

\section{Classification of papers based on ML category, medical device, the IoMT layer.}

Sensor Anomaly Detection for Medical Devices: Herein, the review results of the current subsection related research articles are presented and analyzed, while the highlighted limitations of the studies are given in Table 8 .

In a work performed by Haque et al. (Haque et al. 2015), a sensor anomaly detection system was proposed to differentiate the true from false alarms. The research used a historic data to be compared with the actual sensed data for prediction, whereas majority voting was used for their distinguishing. Consequently, the error was calculated based on dynamic threshold. The proposed method has been implemented in Java environment, supplied by the SMO regression. The results illustrated that the proposed system had a high Detection Rate and low FPR for three medical datasets. Furthermore, referring to the security of signals from deep brain stimulators, the authors in (Abdaoui et al. 2020) built a system for distinguishing false alarms from legitimate ones and classified the attacks using Raspberry Pi3 and deep learning. It was found that deep learning can show an accuracy of about $97 \%$ to learn and predict the fake signals. Also, a webbased application was generated using the web engine (Flask) for that purpose.

Despite the effective application of ML algorithms, they are generating high computational overhead on the low-power embedded frameworks. Rathore et al. (Rathore et al. 2018c) presented a neural network based MLP solution embedded on an FPGA chip system for securing insulin pump devices that are used by diabetic patients. The authors reported an accuracy of $98.1 \%$ for their system in distinguishing the fake from genuine glucose measurements. The reliability of whole framework was improved by $18 \%$ in the case of securing one device and enhanced by $90 \%$ in the case of securing the whole devices.

Khan et al. (Khan et al. 2017) proposed a personal server centered (phone based) Markov modelbased detection mechanism for the detection of multiple intrusions such as forgery attacks, false data insertions, and data modifications in the ECG data for smart medical devices. The extracted features by DWT method were generated representing a feature set followed by their division into sequences. Each sequence's probability was then calculated. The probability value was used as a benchmark to decide if any changes have occurred. Analyzed results showed that the method has a high detection rate with abnormalities of 5\% and $10 \%$ in the dataset. However, it has a higher TNR with reduced running time for both $5 \%$ and $10 \%$ abnormalities. 
438 In another study (Gao \& Thamilarasu 2017), some ML techniques were used, including decision

439

440

441

442

443

444

445

446

447

448

449

450

451

452

453

454

455

456

457

458

459

460

461

462

463

464

465

466

467

468

469

470

471

472

473

474

475

476

477 tree, SVM and K-means, to detect the security attacks in implantable devices. An external detection device was used to monitor the network and the ML classifiers were utilized to detect anomalies on the gateway device for detecting forced device authentication that results in resource depletion of the device. For this purpose, a feature set specific to IMD devices was constructed. Experimental results demonstrated that decision tree-based algorithms achieved the highest detection accuracy, low false positive rate, fast training and prediction speed compared to those of other algorithms.

In another study made by Sehatbakhsh et al. (Sehatbakhsh et al. 2018), SYNDROME was proposed. This method can detect code injection attack in a known program which runs on the system in a real time manner. Statistical based methods such as K-S test and external hardware device were used for detecting signal anomaly. The ability of the method was evaluated by implementing control-flow hijack attacks on a real medical device (syringe pump) embedded system. The evaluation results on using four distinct hardware systems have shown that the proposed model can detect all the attacks with 100\% TPR and zero false positive, while the detection latency was less than two milliseconds.

In a pioneer work carried out by Zhang et al. (Zhang et al. 2013), a security framework was proposed for medical devices monitoring (MedMon). The proposed model was embedded on an external device which listens to all the passed signals coming from or sending to the medical devices by using a multi-layered anomaly detection (behavioral and physical anomalies). The system is useful for those medical devices that do not use encryption. Consequently, the framework either passively notifies the user or actively jams the signal. This solution does not add power overhead on the medical devices without modification to their software and hardware. An insulin delivery device was tested against the proposed method. Results depicted that the system could successfully detect multiple attacks.

For the same purpose, a different approach has been proposed by Newaz et al. (Newaz et al. 2019) which is based on ML data-driven security framework, called HealthGuard, for detecting three types of malicious activities in a SHS by considering interconnected body function. Here, ML based techniques (Artificial Neural Network, Decision Tree, Random Forest, and k-Nearest Neighbor) were used to interpret the physiological signs in multiple attached SHS instruments and compare them to identify the differences in the person's body functions, thereby differentiating benevolent and malicious behaviors. Moreover, there is no need to have user identification for the medical devices and the framework does not increase any overhead on the sensors while collecting data. The proposed system is trained with physiological data obtained from eight IoMT devices containing 12 genuine events consist of 7 normal patient activities and five disease associated activities. Results showed an accuracy of 91\% and F1 score of 90\%. Ben Amor et al. (Ben Amor et al. 2020) suggested an anomaly data detection and separation for the mobile smart healthcare. Two steps were implemented in the study, namely a preprocessing step and a real-time processing step. PCA and Correlation Coefficient were used for feature selection and feature extraction. By this, the system can detect false physiological readings and

Peer) Comput. Sci. reviewing PDF | (CS-2020:10:53665:1:1:NEW 19 Jan 2021) 
478

479

480

481

482

483

484

485

486

487

488

489

490

491

492

493

494

495

496

497

498

499

500

501

502

503

504

505

506

507

508

509

510

511

512

513

514

515

516

can distinguish between the false and true medical functions. Other researchers (Mohamed et al. 2019) attempted to improve the detection efficiency by proposing an intrusion cancellation approach, thereby making the anomaly detection in medical devices efficient. This was achieved by using filters for eliminating noises in the medical data followed by detecting intrusions through statistically analyzed amplitude and frequency. Finally, the detected intrusions were removed to execute the anomaly detection in the medical device for diagnostic purpose. The simulation results applied on two sensor data showed that the system has high TPR and comparable FPR.

Anomaly or malfunction sensor reading resulted from defective sensor nodes or produced by fraudulent foreign entities can contribute to medical error and even mortality in patients. Researchers (Salem et al. 2014) suggested a system to identify abnormalities in Wireless Body Area Network (WBAN) for pervasive patient and health surveillance. The proposed software combines advanced data mining and deep learning technologies with existing sensor fusion techniques. The suggested model uses Support Vector Machine (SVM) to identify irregular incidents of the received sensor data. When an anomaly is detected, a regularly updated and regressive prediction model is used to differentiate between the stable and faulty readings resulting in a higher TPR and lower FNR.

It was recently (Hau \& Lupu 2019) emphasized that identification of fake data injections in low dense Wireless Sensor Networks is important for maintaining the integrity of data, particularly in medical IoT systems. Hence, researchers proposed a framework for detecting false data using anomalies in temporal-attribute correlations between sensor measurements. This method is successful in detecting attacks when more than one sensor is colluding to record coherent measurements (Hau \& Lupu 2019). Nevertheless, with an increase in the number of colluding sensors, the detection efficiency degrades to a point that the detection fails when most of the sensors are colluding.

Furthermore, researchers (Nagdeo \& Mahapatro 2019) have implemented an ML model to separate anomalous data from legitimate sensed data. This research used a combination of ANN with Ensemble LinReg as a detection technique for abnormalities in WBAN sensors. Firstly, normal, and abnormal health records were classified. Secondly, regression methodology was used to recognize the anomaly and real vital data. For the validation purpose, real medical physiological datasets were used. It was concluded that the system was able to effectively detect the anomaly.

Additionally, measured data of blood glucose sensor was examined in order to detect adversarial and accidental data modification intrusions (Verner \& Butvinik 2017). Here, Otsu's thresholding algorithm was used with extra statistical analysis to create different informative feature vectors. Then, linear SVM with different misclassification parameters were used to classify the feature vectors. The obtained results on huge patient's data showed $100 \%$ precision and $99.22 \%$ recall. This demonstrated that data modification attacks can be effectively detected by utilizing the ML approach. 
517 Furthermore, other research groups (Kintzlinger et al. 2020) presented CardiWall system, which

518 is used for detecting and preventing resource depletion attacks against ICDs at programmer

519 device. The system is a collection of six security layers, exploitation of health experts

520 understanding, statistical techniques and one class SVM as the ML technique. To perform the

521 assessment, data were collected over a time span of four years and 775 benevolent clinical

522 commands were used. These were belonging to hundreds of specific patients and 28 malicious

523 clinical prompts established by two cardiac specialists. The evaluation results showed that only

524 two out of the six layers proposed in CardiWall system have provided a high detection

525 capability. One class SVM was failed to obtain a high detection rate because of the problems

526 related to the datasets and a smaller number of features related to the malicious data.. Noticeably,

527 the system achieved an AUC of $94.7 \%$ with a true positive rate (TPR) of $91.4 \%$ and false

528 positive rate (FPR) of $1 \%$.

529 Rathore et al. (Rathore et al. 2019) proposed a Long Short-Term Memory, which is a type of

530 recurrent neural network. It was used for predicting and forecasting different signal patterns of

531 Deep Brain Stimulation (DBS). Usually, Rest Tremor Velocity (RTV) is analyzed to know the

532 neurological disorders intensity. In this way, the authors analyzed RTV values for designing and

533 training the neural network. Multiple attacks have been introduced in the DBS context to

534 simulate and distinguish various attack techniques. To assess the performance of the algorithm in

535 terms of accuracy and reliability, real and false observations were listed and estimated at the run

536 time.

537

538 Table 8:

539 Details of published studies on anomaly and attack detection to the sensors/medical

540 devices.

541

542 Authentication and Access Control: In this section, results and analysis of the relevant papers

543 on this topic are given, while the main features and limitations of the reported works are

544 summarized in Table 9.

545 Rathore et al. (Rathore et al. 2018b) proposed a biometric verification methodology based on

546 ECG, in which the Legendre polynomial extraction and MLP classifier were used for

547 identification and authorization, aiming at securing the data, network, and application layer. The

548 suggested methodology is the first effort to use ECG signals to exploit MLP in authentication.

549 The results were verified on the ECG dataset and showed that it is possible to achieve $100 \%$ test

550 accuracy with 5-degree coefficients when the authorized person is identified.

551 In a research made by Pirbhulal et al. (Pirbhulal et al. 2019), a biometric protection system based

552 on ML technique was introduced, in which the attributes for learning process were derived from

553 ECG signals. Nevertheless, in the testing process, the user is authenticated by using the unique

554 biometric EIs generated from the ECG and the polynomial approximation coefficients. It was

555 concluded that the proposed system can be used for real-time healthcare implementations. 
556 In another work carried out by Mawgoud et al. (Mawgoud et al. 2019), an authentication 557 approach was proposed, which is based on SVM. The authentication was established by 558 incorporating both trust management and SVM at the gateway to recognize the frequency of 559 resource-constraint devices and the timing of access. The proposed approach acts to identify 560 several IoMT sensor artifacts based on their pseudo-random exposure in both frequency and time 561 domains. If the value of the time or frequency domain is the same as its distinctive Pseudo562 Random Binary Sequence (PRBS), the device will be authenticated by the gateway, in which an 563 average trust value of 1.9 and less than 0.5 value are considered as adversary. Results proved that 564 the method is viable for interacting with the IoMT devices.

565 Furthermore, a study was performed by Barros et al (Barros et al. 2019) aiming at reducing the 566 computational cost, in which the features were extracted from ECG signal by utilizing only 567 fiduciary points measured from the acquisition of the signal. A set of ML techniques such as MLP, RF, SVM and NB were used for the classification purpose. The ECG signal of Stress Recognition Database was employed and it was proved that the method can be used for continuous authentication with lower complexity using less than 10 features. Hospital systems with huge number of patients requires proper authentication method. For that purpose, Zhang et al. (Zhang et al. 2018) proposed a hybrid technique that combines fiducial and non-fiducial features for accuracy improvement for authentication in healthcare systems. Feature selection of 2DPCA was used to enhance the accuracy of Linear Discriminant Analysis (LDA) and improving authentication of smart healthcare along with MapReduce. The PQRST peaks were selected as the main fiducial features. For the ECG user recognition, an incrementing training of the LDA algorithm was considered, utilizing the exposed fiducial and non-fiducial features. The authors reported that detection based on fiduciary feature and Fast Fourier Transform has provided a poor precision. Additionally, they concerned that growing the number of features would lead to additional computing effort. Referring back to the individual authentication for daily use of wearable devices, researchers (Shang \& Wu 2019) used photoplethysmography (PPG) signals inspired by hand movements for user authentication on smartwatches. To protect from attackers, the software first senses the beginning and stopping point of any new hand gesture and decides if an attacker is present. This was realized by comparing the features derived from the observed hand movements with those obtained from the regular user. The training samples of the usual consumer have been used to create a local outlier factor (LOF) model. The LOF model has the feature of few parameter modification which helps to easily create a new classifier for a new consumer. In addition, LOF can identify anomalies efficiently. This approach resulted in an overall authentication accuracy of 96:31\% and an overall true rejection rate of at least 91:64\% against two forms of attacks. Authors claimed that this software-based solution can be integrated into any smartwatch with PPG sensors for multi-factor authentication.

594 approach using gait biometric for authenticating users of commercial smart watches. This was

595 realized by extracting the statistical features and person's actions-related features from the 
596

597

598

599

600

601

602

603

604

605

606

607

608

609

610

611

612

613

614

615

616

617

618

619

620

621

622

623

624

625

626

627

628

629

630

631

632

633

634

635

collected data of sensors, thereby improving both accuracy and efficiency. For this purpose, techniques such as filters with RF, K-NN and MLP classifiers were used. Results demonstrated that the system could achieve a higher accuracy by having a reduced feature and fewer sensed dataset. This in turn renders the theoretical architecture more realistic and easily accessible to wearable IoT devices with minimal processing resources and energy efficiency. Furthermore, in a study reported by (Vhaduri \& Poellabauer 2019), a hybrid approach was implemented for biometric authentication in wearable devices. This was achieved by utilizing a three-combination form of course-grain minute-level biometrics: behavioral (step counts), physiological (heart rate), and hybrid (calorie burn and metabolic equivalent of task). An analysis was performed by using 400 Fitbit consumers data that were obtained from a health research collected over 17 months. A combination of filters (KS-test, PC and SD) with SVM of different settings were used. A high accuracy for both sedentary and non-sedentary with low error rates of 0.05 were achieved when a binary SVM was used. It was also proved that hybridizing the biometrics gives better results even during non-sedentary periods.

Mohsen et al. (Mohsen et al. 2019) proposed ECC defined lightweight cooperative authentication scheme to be used in real-time medical wireless sensor networks among physicians/nursing staff, trustworthy databases, sensors and patients. Here, the doctor/nurse can use the system by his/her fingerprint, while patient identity can be verified through continuous monitoring of physiological data (e.g., ECG signals) in every 30 mins to detect the physical theft of the sensor. The server uses PID and ECC feature set as training data and utilizes convolutional neural network. Dynamic identity was applied for user anonymity and mitigating user traceability. Results showed that the scheme is strong against multiple attacks with accepted performance.

Moreover, Punithavathi et al. (Punithavathi et al. 2019) proposed a lightweight approach for cloud cancelable biometric authentication. As such, privacy problems related to biometric utilization can be tackled by getting advantage of cancelable biometric templates. A random projection method was used for generating the cancelable fingerprint template. Fingerprint images were chosen anonymously from publicly accessible databases. After pre-processing and feature extraction, the lightweight random projection method was used to create cancelable fingerprint models. However, authors mentioned that the work's scalability in real world has not been tested.

Rathore et al. (Rathore et al. 2018a) implemented a lightweight approach for trusted authentication using Dynamic Time Warping (DTW) method. A large database from Physionet was used for validating the method and informative features were extracted from ECG using DTW. It was seen that DTW method showed a higher accuracy compared with that of the nonlinear SVM. Additionally, it took less time, while both methods have the same memory complexity.

Moreover, Mohsin et al (Mohsin et al. 2019) designed a secure framework for user verification in two stages of patient authentication. In the first stage, merged RFID and finger vein (FV) features were generated to increase the security levels. In the second phase, a combined 
636 technique of AES encryption, blockchain, and PSO steganography was used for secure

637 transmission of the data. In the evaluation process, 106 samples were chosen from a database

638 comprising of 6000 samples of $\mathrm{FV}$ images. It was seen that the system is strong against spoofing

639 and brute-force attacks, whereby an improvement of $55.56 \%$ was achieved in the secure

640 biometric transmission.

641

642 Table 9:

643 The summary of the studies reported on authentication and access control.

644

645

Intrusion and Malware Detection: Herein, the main achieved results on this topic that were

646 reported in literature are given followed by a summarized comparison of the studies, as shown in 647 Table 10.

648 Begli et al. (Begli et al. 2019) designed a security framework for smart healthcare system, which

649 can be specifically useful for protecting wireless sensor network against unauthorized access and 650 network attacks. In their work, a multiagent based layered architecture was first defined. Then,

651 the IDS was applied using SVM, which is proportional to the level of energy and the sensitivity

652 of the available data of each triple group of the agents. Different rules were used for each layer

653 of the multiagent healthcare. Also, attacks related to healthcare, including eavesdropping attacks,

654 were studied in terms of energy usage and computational cost.

655 Moreover, a multivariate correlation analysis was proposed for the IoMT attacks detection (Itten

$656 \&$ Vadakkumcheril 2016). Triangular based area maps were utilized for analyzing the incoming

657 data's features to formulate a correlation among various features. It was seen that the learning

658 model has a high rate of time usage with increased classification accuracy. The proposed method

659 can differentiate both known and unknown DoS attacks from normal network traffic.

660 Additionally, in a study made by (Schneble \& Thamilarasu 2019a), a massively distributed

661 intrusion detection based on ML was designed and implemented for the Medical Cyber Physical

662 System. Primarily, the notion of Federated Learning was researched to reduce the connectivity

663 and computing expenses associated with conventional ML algorithms. Evaluation was carried

664 out using real patient records against the attacks including DoS, data manipulation and false data

665 injection. Observational findings showed that the proposed system attained a high accuracy of

666 99\% and FPR of 1\% including a decreased communication network's overhead. Moreover, they

667 proved that the program could cope with unevenly distributed data and is a flexible approach that 668 utilizes the computational power of multiple mobile devices. In another work (Odesile \&

669 Thamilarasu 2017), the authors have introduced a mobile agent-based intrusion detection

670 program for WBAN. Different types of sensor agents, and cluster agents are used. Multiple

671 threats were detected in a distributed and hierarchical framework within the healthcare network.

672 ML methods such as NBC, KNN, SVM, RF and DT were applied to sensor nodes for the

673 purpose of providing precise attack detection, followed by choosing an appropriate approach.

674 The system has been tested to be effective in terms of precision and power usage. It was

675 revealed that there is a lack of sufficient researches on the intrusion detection in the medical 
676 cyber-physical system (Schneble \& Thamilarasu 2019b). Since real time attack detection is 677 critical for medical devices, the volume of data analyzed by the IDS should be reduced to 678 maintain optimal frequency detection. Therefore, an effective IDS was proposed by addressing 679 the problem of feature selection to reduce the data dimensionality (Schneble \& Thamilarasu 680 2019b). The findings showed that Laplacian scoring strategies are effective in optimizing the 681 collection of features with reduced resource usage.

682 Furthermore, for the detection of anomaly based intrusion, a stacked autoencoder (SAE) was 683 proposed by $\mathrm{He}$ et al. (He et al. 2019). The SAE was used to extract more informative features 684 and eliminate feature dimensions, which resulted in the reduction of detection overhead. RM et al (RM et al. 2020) applied a hybrid PCA-GWO algorithm for feature selection and DNN classifier for classifying the network attacks. The proposed methodology suits the IoMT devices that are using a unique IP. One-Hot encoding scheme was used for pre-processing the input data. Then, PCA and GWO algorithms were sequentially utilized for further data reduction followed by the use of well-known classifiers for prediction. Results showed that the hybrid PCA-GWO is capable of increasing the detection accuracy by $15 \%$. In addition, the training and classification time was reduced by $32 \%$. For the same purpose, researchers (Thamilarasu 2016) used a multi-objective GA algorithm for the feature selection of WBAN network attack detection. The experimental results showed that the proposed algorithm could include the useful features for detecting a specific attack in the detection process, thereby decreasing the computational complexity. Asfaw et al. (Asfaw et al. 2010) presented a datamining-based model to provide a host-based anomaly and attack detection method for pervasive healthcare systems. When a mobile is requesting from the server, its message is recorded and fed to the classification model. Then, the model classifies the record as benign or malicious depending on the previously recorded history. Eventually, the classifier holds the reactions in a passive fashion, maintaining each specific record with the disruptive behavior and hence detecting the anomalous events. In a recent work performed by Manimurugan et al. (Manimurugan et al. 2020), Deep Belief Network (DBN) was proposed for attacks detection in the IoMT. The measurement criteria used in the study were precision, recall, accuracy, and F1-score. The suggested model achieved positive results across all variables compared to the other techniques. It was claimed that this model can be expanded for detecting several forms of attacks against IoT devices and different databases. Alrashdi et al. (Alrashdi et al. 2019) presented a fog-based attack detection (FBAD) architecture by utilizing an online sequential extreme learning machine (EOS-ELM) collection for monitoring of suspicious behaviors in healthcare system. They proved that the proposed architecture is effectively implemented in the decentralized fog-attack detection by comparing its efficiency to other methods. It was revealed that the decentralized architecture surpassed the centralized framework in terms of detection time and accuracy of classification. Wazid et al. (Wazid et al. 2019) surveyed the malware detection methods in the IoMT network using ML approaches. They elaborated on how serious the malware attacks are, especially botnet 
716 attacks on the three tiers of security and privacy. In the presence of such attacks, the sensitive

717 data of IoT communication may be disclosed, altered or even may not be available to the

718 authorized users. Hence, in the study various types of malware attacks were explored with their

719 symptoms and a taxonomy for the IoMT security was given. Moreover, ML based malware

720 detection methods were discussed.

721 Furthermore, Fernandez Maimo et al.(Fernandez Maimo et al. 2019) used ML techniques for

722 detecting and classifying ransomware attacks in ICE. The NFV/SDN methods were used to

723 isolate and remove contaminated medical equipment and networks. The method was developed

724 to detect recent malwares such as WannaCry, Petya, BadRabbit and PowerGhost. Techniques

725 such as OC-SVM and Naive Bayes have been proved to detect and classify ransomware infecting

726 ICE with respective accuracy and recall of $92.32 \%$ and $99.97 \%$ for the OC-SVM in anomaly

727 detection. This is where the Naive Bayes classifier was able to reach a classification accuracy of

$72899.99 \%$.

729 Shakeel et al. (Shakeel et al. 2018) studied a secure data access and transmission in the IoMT

730 through utilizing the Deep-Q-Network (DQN) methodology. Initially, the IoMT system was

731 analyzed by the deep neural network to authenticate and eliminate any possible malware attacks.

732 The traffic attributes of each request were derived and recorded in the database. The output

733 attribute was then analyzed by using the state feature and associated behavior. Then, the deep

734 neural convolution network was used to classify them into malware and regular data. Results

735 showed that the method has achieved a low error of about 0.12 with malware detection rate of

$73698.79 \%$.

737 Furthermore, with the aim of protecting the brain activity data from attacks in Brain-Computer

738 Interface (BCI) systems such as Electroencephalography (EEG) and fraud BCI program (e.g.

739 game), which lets a malicious entity to obtain the user's brain activities, researchers

740 demonstrated that a ML method can anticipate relevant identity characteristics by studying

741 resting-state EEG (rsEEG) records of a person's brain activity (Landau et al. 2020). A complete

742 collection of raw rsEEG tests along with dissociation degree and executive function (EF)

743 assessment indicators were used for 162 subjects in the test. Their study concluded that

744 breaching those identical brain activities are possible if proper security measures are not taken

745 into consideration.

Table 10:

Summary of the studies reported on intrusion and malware detection.

\section{Discussion}

753

In this section, the main outcomes of the reviewed studies are elaborated and discussed aiming at

754 achieving fruitful answers to each of the research questions, respectively. 
RQ1: What is the current state of the art and direction of study in the loMT

757 security using ML?

One can see from Fig. 7 that $37 \%$ of the research articles were devoted to detect anomaly at sensors or medical devices. This indicated that in the past years, the main focus was on detecting the intrusions such as false data injection, resource depletion attacks, behavioral and physical attacks against medical devices. This can be attributed to the fact that these attacks are serious and they lead to significant health issues. For instance, it may lead to death in the case of attacks to the implantable medical devices (Alsubaei et al. 2019b; Hatzivasilis et al. 2019; Yaacoub et al. 2020).

Also, intrusion and malware attack detections received a considerable attention, counting for $35 \%$ of the reported studies ( $7 \%$ for malware and $28 \%$ for other attacks). Nevertheless, majority of the papers were found to have focused on NIDS. On the other hand, papers that used different strategies to solve the authentication and access control issues were found to take $28 \%$. However, as authentication is computationally heavy for the IoMT devices, the current direction of research is to apply lightweight mechanisms (Aghili et al. 2019a; Wu et al. 2018) by using sensor physiological data to reduce the computation load on the device.

\section{Figure 7: Papers distribution by the direction and problem-solving domain.}

\section{RQ 2: What kind of data and tools are used for applying $M L$ techniques in the loMT security?}

Machine Learning methods are data dependent as they learn from these data overtime and decide intelligently based on their learning ability, amount and quality of the data. For this reason, in our study we have paid attention to this matter and we have analyzed all the selected research articles based on the type of data they used for decision making and learning process. It can be seen from Fig. 8 that most of the papers have used historical benchmark data, of which $9 \%$ have used network data, while $51 \%$ have used sensors and physiological data. This is mainly because most of the methods were to find anomalies in the sensors and to use device authentication as security solution.. On the other hand, $26 \%$ of the papers have used simulated or emulated data. However, some of the studies have not given the source of their data or did not mention it at all. For this category, we have given the label not available or not given. This group of papers provides $14 \%$ of the whole selected papers.

To further answer the above research question, software and hardware tools used and reported in the reviewed studies are analyzed. Figure 9 shows the used software tools and programs in the

Figure 8. The type of data used by the researchers to conduct their research. reviewed studies. Tools used by the studied works were mainly Network/ Sensor Simulators with ML tools. However, we have excluded those studies that used simulation but did not mention its 
795

796

797

798

799

800

801

802

803

804

805

806

807

808

809

810

811

812

813

814

815

816

817

818

819

820

821

822

823

824

825

826

827

828

829

830

831

832

833

834

835

tool. For this reason, the percentage of the simulation tools is less than expected. Furthermore, $25 \%$ of the studies did not give the tools used in their studies. The remaining were mainly programming tools for ML purpose. We can see that MATLAB has been used more than the rest of the tools. Python also gained good attention in the current years. In addition, Weka tool has been used frequently, which counts for $9 \%$ of the studies. Additionally, Keras and Sckit-learn libraries were used with $8 \%$ and $6 \%$ by the studies, respectively. Those represent open-source libraries are usually used with Python. Moreover, in the reviewed studies, some works have used testbeds and hardware tools, while few of them reported their tools. Figure 10 shows the number of those tools that have been used. It was found that six types of devices and hardware tools were used and reported in the studies.

Figure 9: Software and tools used by the studies.

Figure 10: Devices and hardware tools used in the studies.

\section{RQ 3: How ML techniques are effectively applied by the studies and what are their limitations?}

Through a critical analysis of the current works, we can conclude that traditional ML techniques may fail if proper considerations are not given to some metrics such as computational complexity and energy usage. ML performance is reduced when few data are used. However, the IoMT devices are resource limited such as (IMDs) and using a huge data analysis on these devices is resulted in degrading their lifespan. For these reasons, one should take a balance between these two aspects. From our analysis of the reviewed papers, we have found that a small portion of the studies have used lightweight approaches. The pie chart shown in Fig. 11-a illustrates that only $14 \%$ of the studies have used lightweight approach. Additionally, 12\% of the studies have used low complexity approaches, that means it is not exactly lightweight but not heavy. The rest of the studies either did not require this feature in their system or failed to apply it. Furthermore, real time ML techniques are crucial for the IoMT, especially in attack and intrusion detection.

Because the IoMT networks are dealing with streaming data and some of the devices never stop from working, a continuous and fast detection of attacks are required. It is seen from Fig. 11-b that $19 \%$ of the studies were used real time approach, while $12 \%$ of the studies have used low complex approaches that are not exactly real time but have approached it. Nevertheless, the other $67 \%$ of the works were offline. Additionally, the studies focused on network attack detection paid less attention to distributed attack detection. As can be seen in Fig. 12 that only $12 \%$ of the studied have used decentralized models, while the rest were centralized. However, a hybrid of the methods was considered as a better approach.

Figure 11: Analysis of the studies in terms of (a) complexity and (b) real time analysis

Figure 12: Details of the studies in terms of placement. 
836

837

838

839

840

841

842

843

844

845

846

847

848

849

850

851

852

853

854

855

856

857

858

859

860

861

862

863

864

865

866

867

868

869

870

871

872

873

874

Based on the studies gaps that were assigned previously, it is found that majority of the studies have focused on improving the traditional evaluation metrics for their ML models such as high (accuracy, recall, precision) and low (FP, FN). However, performance metrics such as memory (space), CPU, time, and energy overhead were neglected. Additionally, most of the techniques of attack detection were performed in an isolated offline environment. However, one should consider simulation/hardware implementation to represent a real IoT setting. Also, decentralized and hybrid approaches are much compatible for the IoMT than centralized one, which was again not common among the studies. Furthermore, we have noticed that the datasets used by the attack and intrusion detection methods were out of date and some of them do not represent the current IoMT system. Moreover, sensitive, and private data usage should be avoided in attack and anomaly detection tasks which was also given a minor attention. Therefore, there should be a trade-off among preserving privacy, high accuracy, and computational complexity. Another challenge that should be considered is the risk of adversarial attacks on ML techniques themselves. An attacker who have enough knowledge on how the ML techniques work with the data can manipulate the data at training or testing stage to fool the ML method. Hence, the proposed methods should be strong enough against the adversarial attacks.

\section{Limitations}

The underlying drawbacks of this research are: i) Selection bias: This study focuses on literature research, which may have unintentionally omitted most recent non-scholarly advancements or scholarly articles that yet to be published at the time of preparing this study. ii) Publication bias: Some of the studies may have been discarded since their full paper was not accessible. iii) Descriptive bias: Despite the efforts made to present the background comprehensively, this SLR is combining many topics that may need someone to refer to the external sources for a deep understanding.

\section{Conclusions}

In this study, a comprehensive Systematic Literature Review (SLT) was given about the IoMT security and privacy issues and how Machine Learning (ML) methods are used for solving them. By examining the content of the study, including methods, good features, limitations, tools, and datasets, the designated research questions were answered. Findings of this study showed that ML techniques are effective in addressing the IoMT security issues with promising results. Majority of the studies was devoted to device layer or body area network security since attacks on devices such as IMDs are seriously affecting the patient's health and life. The security solutions for such devices were sensor anomaly detection and device authentication and access control. Furthermore, securing the network layer was seen among the studies that used attack and malware detection strategies.

Peer] Comput. Sci. reviewing PDF | (CS-2020:10:53665:1:1:NEW 19 Jan 2021) 
875 Moreover, the tools and environment of the current works are a combination of network

876 simulators and ML tools with more focus on the latter. Additionally, there is a lack of relevant

877 datasets, especially in the intrusion detection. Most of the studies focused on improving the

878 common ML algorithms evaluation metrics such as high accuracy and low FPR. However, since

879 the IoMT devices are characterized with shortage in power and small memory and processor,

880 there should be a balance between security and maintaining resources lifespan during the

881 adaption of these solutions. We have concluded that traditional ML techniques may fail if proper

882 consideration is not given to some metrics such as resource complexity, time complexity, and

883 energy usage. It was noticed that a vast majority of the studies ignored these criteria in the

884 evaluation of their proposed models. Therefore, ML techniques are vital in the application of the

885 IoMT security. However, future studies should focus on how to use ML in a proper way to

886 concede the nature of the IoMT.

887

888

889

890

891

892

893

894

895

896

897

898

899

900

901

902

903

904

905

906

907

908

909

910

911

912

913

914

915

916

\section{References}

Abdaoui A, Al-Ali A, Riahi A, Mohamed A, Du X, and Guizani M. 2020. Secure medical treatment with deep learning on embedded board. Energy Efficiency of Medical Devices and Healthcare Applications: Elsevier, 131-151.

Abhishek NV, Lim TJ, Sikdar B, and Tandon A. 2018. An intrusion detection system for detecting compromised gateways in clustered loT networks. 2018 IEEE International Workshop Technical Committee on Communications Quality and Reliability (CQR): IEEE. p 1-6.

Aghili SF, Mala H, Kaliyar P, and Conti M. 2019a. SecLAP: Secure and lightweight RFID authentication protocol for Medical IoT. Future Generation Computer Systems 101:621-634. https://doi.org/10.1016/i.future.2019.07.004

Aghili SF, Mala H, Shojafar M, and Peris-Lopez P. 2019b. LACO: Lightweight Three-Factor Authentication, Access Control and Ownership Transfer Scheme for E-Health Systems in loT. Future Generation Computer Systems 96:410-424. https://doi.org/10.1016/j.future.2019.02.020

Ahad A, Tahir M, and Yau KA. 2019. 5G-Based Smart Healthcare Network: Architecture, Taxonomy, Challenges and Future Research Directions. IEEE Access 7:100747-100762. 10.1109/ACCESS.2019.2930628

Ahmad B, Jian W, Ali ZA, Tanvir S, and Khan MSA. 2019. Hybrid anomaly detection by using clustering for wireless sensor network. Wireless Personal Communications 106:1841-1853.

Al Shorman A, Faris H, and Aljarah I. 2019. Unsupervised intelligent system based on one class support vector machine and Grey Wolf optimization for loT botnet detection. Journal of Ambient Intelligence and Humanized Computing:1-17.

Alassaf N, and Gutub A. 2019. Simulating Light-Weight-Cryptography Implementation for loT Healthcare Data Security Applications. International Journal of E-Health and Medical Communications 10:115. 10.4018/ijehmc. 2019100101

Alimadadi A, Aryal S, Manandhar I, Munroe PB, Joe B, and Cheng X. 2020. Artificial Intelligence and Machine Learning to Fight COVID-19. American Physiological Society Rockville, MD.

Alrashdi I, Alqazzaz A, Alharthi R, Aloufi E, Zohdy MA, and Ming H. 2019. FBAD: Fog-based attack detection for loT healthcare in smart cities. 2019 IEEE 10th Annual Ubiquitous Computing, Electronics \& Mobile Communication Conference (UEMCON): IEEE. p 0515-0522. 
917

918

919

920

921

922

923

924

925

926

927

928

929

930

931

932

933

934

935

936

937

938

939

940

941

942

943

944

945

946

947

948

949

950

951

952

953

954

955

956

957

958

959

960

961

962

963

964

Alsubaei F, Abuhussein A, and Shiva S. 2019a. A Framework for Ranking loMT Solutions Based on Measuring Security and Privacy. In: Arai K, Bhatia R, and Kapoor S, eds. Proceedings of the Future Technologies Conference. Cham: Springer International Publishing Ag, 205-224.

Alsubaei F, Abuhussein A, and Shiva S. 2019b. Ontology-Based Security Recommendation for the Internet of Medical Things. IEEE Access 7:48948-48960. 10.1109/access.2019.2910087

Aluvalu R. 2020. Intrusion Detection System for the loT: A Comprehensive Review. Proceedings of the 11th International Conference on Soft Computing and Pattern Recognition (SoCPaR 2019): Springer Nature. p 235.

Aman AHM, Hassan WH, Sameen S, Attarbashi ZS, Alizadeh M, and Latiff LA. 2020. IoMT amid COVID-19 pandemic: Application, architecture, technology, and security. Journal of Network and Computer Applications:102886.

Amanullah MA, Habeeb RAA, Nasaruddin FH, Gani A, Ahmed E, Nainar ASM, Akim NM, and Imran M. 2020. Deep learning and big data technologies for loT security. Computer Communications 151:495-517.

Anthi E, Williams L, and Burnap P. 2018. Pulse: an adaptive intrusion detection for the internet of things. Ardabili SF, Mosavi A, Ghamisi P, Ferdinand F, Varkonyi-Koczy AR, Reuter U, Rabczuk T, and Atkinson PM. 2020. Covid-19 outbreak prediction with machine learning. Available at SSRN 3580188.

Arshad J, Azad MA, Amad R, Salah K, Alazab M, and Iqbal R. 2020. A Review of Performance, Energy and Privacy of Intrusion Detection Systems for loT. Electronics 9:629.

Asfaw B, Bekele D, Eshete B, Villafiorita A, and Weldemariam K. 2010. Host-based anomaly detection for pervasive medical systems. 2010 Fifth International Conference on Risks and Security of Internet and Systems (CRiSIS): IEEE. p 1-8.

Bahşi H, Nõmm S, and La Torre FB. 2018. Dimensionality reduction for machine learning based iot botnet detection. 2018 15th International Conference on Control, Automation, Robotics and Vision (ICARCV): IEEE. p 1857-1862.

Barros A, Rosário D, Resque $P$, and Cerqueira E. 2019. Heart of IoT: ECG as biometric sign for authentication and identification. 2019 15th International Wireless Communications \& Mobile Computing Conference (IWCMC): IEEE. p 307-312.

Begli M, Derakhshan F, and Karimipour H. 2019. A layered intrusion detection system for critical infrastructure using machine learning. 2019 IEEE 7th International Conference on Smart Energy Grid Engineering (SEGE): IEEE. p 120-124.

Ben Amor L, Lahyani I, and Jmaiel M. 2020. AUDIT: AnomaloUs data Detection and Isolation approach for mobile healThcare systems. Expert Systems 37:e12390.

Bostami B, Ahmed M, and Choudhury S. 2019. False Data Injection Attacks in Internet of Things. Performability in Internet of Things: Springer, 47-58.

Bostani H, and Sheikhan M. 2017. Hybrid of anomaly-based and specification-based IDS for Internet of Things using unsupervised OPF based on MapReduce approach. Computer Communications 98:52-71.

Burhan M, Rehman RA, Khan B, and Kim B-S. 2018. IoT elements, layered architectures and security issues: A comprehensive survey. Sensors 18:2796.

Butun I, Kantarci B, and Erol-Kantarci M. 2015. Anomaly detection and privacy preservation in cloudcentric Internet of Things. 2015 IEEE International Conference on Communication Workshop (ICCW): IEEE. p 2610-2615.

Cao L. 2017. Data science: a comprehensive overview. ACM Computing Surveys (CSUR) 50:1-42.

Chakraborty A, Alam M, Dey V, Chattopadhyay A, and Mukhopadhyay D. 2018. Adversarial attacks and defences: A survey. arXiv preprint arXiv:181000069.

Cui L, Yang S, Chen F, Ming Z, Lu N, and Qin J. 2018. A survey on application of machine learning for Internet of Things. International Journal of Machine Learning and Cybernetics 9:1399-1417.

Peer] Comput. Sci. reviewing PDF | (CS-2020:10:53665:1:1:NEW 19 Jan 2021) 
965

da Costa KA, Papa JP, Lisboa CO, Munoz R, and de Albuquerque VHC. 2019. Internet of Things: A survey on machine learning-based intrusion detection approaches. Computer Networks 151:147-157.

Dang LM, Piran M, Han D, Min K, and Moon H. 2019. A survey on internet of things and cloud computing for healthcare. Electronics 8:768.

Davis J. 2020a. Ransomware Attacks Cost Healthcare Sector At Least $\$ 160 \mathrm{M}$ Since 2016. Available at https://healthitsecurity.com/news/ransomware-attacks-cost-healthcare-sector-at-least-160msince-2016 (accessed 11/1/2020.

Davis J. 2020b. US Ransomware Attacks Doubled in Q3; Healthcare Sector Most Targeted. Available at https://healthitsecurity.com/news/us-ransomware-attacks-doubled-in-q3-healthcare-sectormost-targeted (accessed 2/1/2021.

Dimitrov DV. 2016. Medical internet of things and big data in healthcare. Healthcare informatics research 22:156-163.

Din IU, Almogren A, Guizani M, and Zuair M. 2019. A Decade of Internet of Things: Analysis in the Light of Healthcare Applications. IEEE Access 7:89967-89979. 10.1109/access.2019.2927082

Diro AA, and Chilamkurti N. 2018. Distributed attack detection scheme using deep learning approach for Internet of Things. Future Generation Computer Systems 82:761-768.

Durga S, Nag R, and Daniel E. 2019. Survey on machine learning and deep learning algorithms used in internet of things (IOT) healthcare. 2019 3rd International Conference on Computing Methodologies and Communication (ICCMC): IEEE. p 1018-1022.

Elrawy MF, Awad Al, and Hamed HF. 2018. Intrusion detection systems for loT-based smart environments: a survey. Journal of Cloud Computing 7:21.

Escamilla-Ambrosio P, Rodríguez-Mota A, Aguirre-Anaya E, Acosta-Bermejo R, and Salinas-Rosales M. 2018. Distributing computing in the internet of things: cloud, fog and edge computing overview. NEO 2016: Springer, 87-115.

Eskandari M, Janjua ZH, Vecchio M, and Antonelli F. 2020. Passban IDS: An intelligent anomaly based intrusion detection system for loT edge devices. IEEE Internet of Things Journal.

Farahani B, Firouzi F, Chang V, Badaroglu M, Constant N, and Mankodiya K. 2018. Towards fog-driven loT eHealth: Promises and challenges of loT in medicine and healthcare. Future Generation Computer Systems 78:659-676.

Farroha J. 2019. Security Analysis and Recommendations for Al/ML Enabled Automated Cyber Medical Systems. In: Ahmad F, ed. Big Data: Learning, Analytics, and Applications. Bellingham: Spie-Int Soc Optical Engineering.

Fernandez Maimo L, Huertas Celdran A, Perales Gomez AL, Garcia Clemente FJ, Weimer J, and Lee I. 2019. Intelligent and dynamic ransomware spread detection and mitigation in integrated clinical environments. Sensors 19:1114.

Firouzi F, Rahmani AM, Mankodiya K, Badaroglu M, Merrett GV, Wong P, and Farahani B. 2018. Internetof-Things and big data for smarter healthcare: From device to architecture, applications and analytics. Elsevier.

Gao S, and Thamilarasu G. 2017. Machine-learning classifiers for security in connected medical devices. 2017 26th International Conference on Computer Communication and Networks (ICCCN): IEEE. p 1-5.

Gheisari M, Wang G, and Bhuiyan MZA. 2017. A survey on deep learning in big data. 2017 IEEE international conference on computational science and engineering (CSE) and IEEE international conference on embedded and ubiquitous computing (EUC): IEEE. p 173-180.

Grammatikis PIR, Sarigiannidis PG, and Moscholios ID. 2019. Securing the Internet of Things: Challenges, threats and solutions. Internet of Things 5:41-70.

Gupta R, Tanwar S, Tyagi S, and Kumar N. 2020a. Machine learning models for secure data analytics: A taxonomy and threat model. Computer Communications 153:406-440.

Peer] Comput. Sci. reviewing PDF | (CS-2020:10:53665:1:1:NEW 19 Jan 2021) 
1013

1014

1015

1016

1017

1018

1019

1020

1021

1022

1023

1024

1025

1026

1027

1028

1029

1030

1031

1032

1033

1034

1035

1036

1037

1038

1039

1040

1041

1042

1043

1044

1045

1046

1047

1048

1049

1050

1051

1052

1053

1054

1055

1056

1057

1058

1059
Gupta S, Venugopal V, Mahajan V, Gaur S, Barnwal M, and Mahajan H. 2020b. HIPAA, GDPR and Best Practice Guidelines for preserving data security and privacy-What Radiologists should know. European Congress of Radiology-ECR 2020.

Hameed SS, Hassan R, and Muhammad FF. 2017. Selection and classification of gene expression in autism disorder: Use of a combination of statistical filters and a GBPSO-SVM algorithm. PloS one 12.

Haque SA, Rahman M, and Aziz SM. 2015. Sensor anomaly detection in wireless sensor networks for healthcare. Sensors 15:8764-8786.

Hasan M, Islam MM, Zarif MII, and Hashem M. 2019. Attack and anomaly detection in loT sensors in loT sites using machine learning approaches. Internet of Things 7:100059.

Hassija V, Chamola V, Saxena V, Jain D, Goyal P, and Sikdar B. 2019. A survey on loT security: application areas, security threats, and solution architectures. IEEE Access 7:82721-82743.

Hatzivasilis G, Soultatos O, loannidis S, Verikoukis C, Demetriou G, Tsatsoulis Cl, and leee. 2019. Review of Security and Privacy for the Internet of Medical Things (IoMT) Resolving the protection concerns for the novel circular economy bioinformatics. 2019 15th International Conference on Distributed Computing in Sensor Systems. New York: leee, 457-464.

Hau Z, and Lupu EC. 2019. Exploiting Correlations to Detect False Data Injections in Low-Density Wireless Sensor Networks. Proceedings of the 5th on Cyber-Physical System Security Workshop. p 1-12.

He D, Qiao Q, Gao Y, Zheng J, Chan S, Li J, and Guizani N. 2019. Intrusion Detection Based on Stacked Autoencoder for Connected Healthcare Systems. IEEE Network 33:64-69.

He D, Ye R, Chan S, Guizani M, and Xu Y. 2018. Privacy in the Internet of Things for smart healthcare. IEEE Communications Magazine 56:38-44.

Hei X, Du X, Wu J, and Hu F. 2010. Defending resource depletion attacks on implantable medical devices. 2010 IEEE global telecommunications conference GLOBECOM 2010: IEEE. p 1-5.

Hussain F, Hussain R, Hassan SA, and Hossain E. 2020. Machine learning in loT security: current solutions and future challenges. IEEE Communications Surveys \& Tutorials.

Ibitoye O, Shafiq O, and Matrawy A. 2019. Analyzing adversarial attacks against deep learning for intrusion detection in loT networks. 2019 IEEE Global Communications Conference (GLOBECOM): IEEE. p 1-6.

Itten A, and Vadakkumcheril GT. 2016. ENHANCED INTRUSION DETECTION SYSTEM IN MEDICAL CYBER PHYSICAL SYSTEMS USING MULTIVARIATE CORRELATION ANALYSIS.

Jaigirdar FT, Rudolph C, and Bain C. 2019. Can I Trust the Data I See? A Physician's Concern on Medical Data in loT Health Architectures. Proceedings of the Australasian Computer Science Week Multiconference. p 1-10.

Jan SU, Ahmed S, Shakhov V, and Koo I. 2019. Toward a lightweight intrusion detection system for the internet of things. IEEE Access 7:42450-42471.

Khan FA, Haldar NAH, Ali A, Iftikhar M, Zia TA, and Zomaya AY. 2017. A continuous change detection mechanism to identify anomalies in ECG signals for WBAN-based healthcare environments. IEEE Access 5:13531-13544.

Kintzlinger M, Cohen A, Nissim N, Rav-Acha M, Khalameizer V, Elovici Y, Shahar Y, and Katz A. 2020. CardiWall: A Trusted Firewall for the Detection of Malicious Clinical Programming of Cardiac Implantable Electronic Devices. IEEE Access 8:48123-48140.

Kubat M. 2017. An introduction to machine learning: Springer.

Landau O, Cohen A, Gordon S, and Nissim N. 2020. Mind your privacy: Privacy leakage through BCI applications using machine learning methods. Knowledge-Based Systems:105932.

Li Q, Li W, Wang J, and Cheng M. 2019. A SQL Injection Detection Method Based on Adaptive Deep Forest. IEEE Access 7:145385-145394.

Peer] Comput. Sci. reviewing PDF | (CS-2020:10:53665:1:1:NEW 19 Jan 2021) 
1060

1061

1062

1063

1064

1065

1066

1067

1068

1069

1070

1071

1072

1073

1074

1075

1076

1077

1078

1079

1080

1081

1082

1083

1084

1085

1086

1087

1088

1089

1090

1091

1092

1093

1094

1095

1096

1097

1098

1099

1100

1101

1102

1103

1104

1105

1106

Liang W, Huang W, Long J, Zhang K, Li K-C, and Zhang D. 2020. Deep reinforcement learning for resource protection and real-time detection in IoT environment. IEEE Internet of Things Journal.

Liu CH, Lin Q, and Wen S. 2018. Blockchain-enabled data collection and sharing for industrial loT with deep reinforcement learning. IEEE Transactions on Industrial Informatics 15:3516-3526.

Lopez-Martin M, Carro B, Sanchez-Esguevillas A, and Lloret J. 2017. Conditional variational autoencoder for prediction and feature recovery applied to intrusion detection in iot. Sensors 17:1967.

Ma Y, Wang Y, Yang J, Miao Y, and Li W. 2017. Big Health Application System based on Health Internet of Things and Big Data. IEEE Access 5:7885-7897. 10.1109/ACCESS.2016.2638449

Maleh Y, Ezzati A, Qasmaoui Y, and Mbida M. 2015. A global hybrid intrusion detection system for wireless sensor networks. Procedia Computer Science 52:1047-1052.

Manimurugan S, Almutairi S, Aborokbah MM, Chilamkurti N, Ganesan S, and Patan R. 2020. Effective Attack Detection in Internet of Medical Things Smart Environment using a Deep Belief Neural Network. IEEE Access.

Marjani M, Nasaruddin F, Gani A, Karim A, Hashem IAT, Siddiqa A, and Yaqoob I. 2017. Big loT data analytics: architecture, opportunities, and open research challenges. IEEE Access 5:5247-5261.

Mawgoud AA, Karadawy Al, and Tawfik BS. 2019. A Secure Authentication Technique in Internet of Medical Things through Machine Learning. arXiv preprint arXiv:191212143.

McMahon E, Williams R, El M, Samtani S, Patton M, and Chen H. 2017. Assessing medical device vulnerabilities on the Internet of Things. 2017 IEEE International Conference on Intelligence and Security Informatics (ISI): IEEE. p 176-178.

Meidan Y, Bohadana M, Mathov Y, Mirsky Y, Shabtai A, Breitenbacher D, and Elovici Y. 2018. N-BaloTnetwork-based detection of loT botnet attacks using deep autoencoders. IEEE Pervas Comput 17 (3): 12-22.

Midi D, Rullo A, Mudgerikar A, and Bertino E. 2017. Kalis-A system for knowledge-driven adaptable intrusion detection for the Internet of Things. 2017 IEEE 37th International Conference on Distributed Computing Systems (ICDCS): IEEE. p 656-666.

Miyato T, Maeda S-i, Koyama M, and Ishii S. 2018. Virtual adversarial training: a regularization method for supervised and semi-supervised learning. IEEE transactions on pattern analysis and machine intelligence 41:1979-1993.

Mohamed MB, Meddeb-Makhlouf A, and Fakhfakh A. 2019. Intrusion cancellation for anomaly detection in healthcare applications. 2019 15th International Wireless Communications \& Mobile Computing Conference (IWCMC): IEEE. p 313-318.

Mohsen NR, Ying B, and Nayak A. 2019. Authentication Protocol for Real-Time Wearable Medical Sensor Networks Using Biometrics and Continuous Monitoring. 2019 International Conference on Internet of Things (iThings) and IEEE Green Computing and Communications (GreenCom) and IEEE Cyber, Physical and Social Computing (CPSCom) and IEEE Smart Data (SmartData): IEEE. p 1199-1206.

Mohsin A, Zaidan A, Zaidan B, Albahri O, Albahri A, Alsalem M, and Mohammed K. 2019. Based blockchain-PSO-AES techniques in finger vein biometrics: A novel verification secure framework for patient authentication. Computer Standards \& Interfaces 66:103343.

Mosenia A, and Jha NK. 2016. A comprehensive study of security of internet-of-things. IEEE Transactions on Emerging Topics in Computing 5:586-602.

Mozaffari-Kermani M, Sur-Kolay S, Raghunathan A, and Jha NK. 2014. Systematic poisoning attacks on and defenses for machine learning in healthcare. IEEE journal of biomedical and health informatics 19:1893-1905.

Musale P, Baek D, Werellagama N, Woo SS, and Choi BJ. 2019. You walk, we authenticate: Lightweight seamless authentication based on gait in wearable loT systems. IEEE Access 7:37883-37895.

Peer] Comput. Sci. reviewing PDF | (CS-2020:10:53665:1:1:NEW 19 Jan 2021) 
1107

1108

1109

1110

1111

1112

1113

1114

1115

1116

1117

1118

1119

1120

1121

1122

1123

1124

1125

1126

1127

1128

1129

1130

1131

1132

1133

1134

1135

1136

1137

1138

1139

1140

1141

1142

1143

1144

1145

1146

1147

1148

1149

1150

1151

1152

1153
Nagdeo SK, and Mahapatro J. 2019. Wireless Body Area Network Sensor Faults and Anomalous Data Detection and Classification using Machine Learning. 2019 IEEE Bombay Section Signature Conference (IBSSC): IEEE. p 1-6.

Nanayakkara N, Halgamuge M, and Syed A. 2019. Security and Privacy of Internet of Medical Things (IoMT) Based Healthcare Applications: A Review.

Newaz A, Sikder AK, Rahman MA, and Uluagac AS. 2020. A Survey on Security and Privacy Issues in Modern Healthcare Systems: Attacks and Defenses. arXiv preprint arXiv:200507359.

Newaz Al, Sikder AK, Rahman MA, and Uluagac AS. 2019. Healthguard: A machine learning-based security framework for smart healthcare systems. 2019 Sixth International Conference on Social Networks Analysis, Management and Security (SNAMS): IEEE. p 389-396.

Nguyen DC, Pathirana PN, Ding M, and Seneviratne A. 2019. Blockchain for Secure EHRs Sharing of Mobile Cloud Based E-Health Systems. IEEE Access 7:66792-66806. 10.1109/access.2019.2917555

Noor MM, and Hassan WH. 2019. Current research on Internet of Things (IOT) security: A survey. Computer Networks 148:283-294.

Odesile A, and Thamilarasu G. 2017. Distributed intrusion detection using mobile agents in wireless body area networks. 2017 Seventh International Conference on Emerging Security Technologies (EST): IEEE. p 144-149.

Pandey P, and Litoriya R. 2020. Elderly care through unusual behavior detection: A disaster management approach using loT and intelligence. IBM Journal of Research and Development 64:15:11-15:11. 10.1147/JRD.2019.2947018

Pandey R, Gautam V, Bhagat K, and Sethi T. 2020. A Machine Learning Application for Raising WASH Awareness in the Times of Covid-19 Pandemic. arXiv preprint arXiv:200307074.

Pannu A. 2015. Artificial intelligence and its application in different areas. Artificial Intelligence 4:79-84.

Parra GDLT, Rad P, Choo K-KR, and Beebe N. 2020. Detecting Internet of Things attacks using distributed deep learning. Journal of Network and Computer Applications:102662.

Patel N. 2020. Social Engineering As an Evolutionary Threat to Information Security in Healthcare Organizations. Jurnal Administrasi Kesehatan Indonesia 8.

Pirbhulal S, Pombo N, Felizardo V, Garcia N, Sodhro AH, and Mukhopadhyay SC. 2019. Towards Machine Learning Enabled Security Framework for loT-based Healthcare. 2019 13th International Conference on Sensing Technology (ICST): IEEE. p 1-6.

Pramanik MI, Lau RY, Demirkan H, and Azad MAK. 2017. Smart health: Big data enabled health paradigm within smart cities. Expert Systems with Applications 87:370-383.

Punithavathi P, Geetha S, Karuppiah M, Islam SH, Hassan MM, and Choo K-KR. 2019. A lightweight machine learning-based authentication framework for smart loT devices. Information Sciences 484:255-268.

Qu G, and Yuan L. 2014. Design THINGS for the Internet of Things-An EDA perspective. 2014 IEEE/ACM international conference on Computer-Aided Design (ICCAD): IEEE. p 411-416.

Rahman MA, and Mohsenian-Rad H. 2012. False data injection attacks with incomplete information against smart power grids. 2012 IEEE Global Communications Conference (GLOBECOM): IEEE. $p$ 3153-3158.

Rahmani AM, Gia TN, Negash B, Anzanpour A, Azimi I, Jiang M, and Liljeberg P. 2018. Exploiting smart eHealth gateways at the edge of healthcare Internet-of-Things: A fog computing approach. Future Generation Computer Systems 78:641-658.

Rathore H, Al-Ali A, Mohamed A, Du X, and Guizani M. 2018a. DTW based authentication for wireless medical device security. 2018 14th International Wireless Communications \& Mobile Computing Conference (IWCMC): IEEE. p 476-481. 
1154

1155

1156

1157

1158

1159

1160

1161

1162

1163

1164

1165

1166

1167

1168

1169

1170

1171

1172

1173

1174

1175

1176

1177

1178

1179

1180

1181

1182

1183

1184

1185

1186

1187

1188

1189

1190

1191

1192

1193

1194

1195

1196

1197

1198

1199

1200

Rathore H, Al-Ali AK, Mohamed A, Du X, and Guizani M. 2019. A Novel Deep Learning Strategy for Classifying Different Attack Patterns for Deep Brain Implants. IEEE Access 7:24154-24164.

Rathore H, Fu C, Mohamed A, Al-Ali A, Du X, Guizani M, and Yu Z. 2018b. Multi-layer security scheme for implantable medical devices. Neural Computing and Applications:1-14.

Rathore H, Wenzel L, Al-Ali AK, Mohamed A, Du X, and Guizani M. 2018c. Multi-layer perceptron model on chip for secure diabetic treatment. IEEE Access 6:44718-44730.

Rathore S, and Park JH. 2018. Semi-supervised learning based distributed attack detection framework for loT. Applied Soft Computing 72:79-89.

RM SP, Maddikunta PKR, Parimala M, Koppu S, Reddy T, Chowdhary CL, and Alazab M. 2020. An effective feature engineering for DNN using hybrid PCA-GWO for intrusion detection in loMT architecture. Computer Communications.

Roopak M, Tian GY, and Chambers J. 2020. Multi-objective-based feature selection for DDoS attack detection in loT networks. IET Networks 9:120-127.

Russom P. 2011. Big data analytics. TDWI best practices report, fourth quarter 19:1-34.

S. O'Dea S. 2020. Data volume of loT connected devices worldwide 2018 and 2025. Available at https://www.statista.com/statistics/1017863/worldwide-iot-connected-devices-data-size/.

Sadoughi F, Behmanesh A, and Sayfouri N. 2020. Internet of Things in Medicine: A Systematic Mapping Study. Journal of Biomedical Informatics:103383.

Saeed A, Ahmadinia A, Javed A, and Larijani H. 2016. Random neural network based intelligent intrusion detection for wireless sensor networks. Procedia Computer Science 80:2372-2376.

Saheb T, and Izadi L. 2019. Paradigm of loT big data analytics in healthcare industry: a review of scientific literature and mapping of research trends. Telematics and Informatics.

Salem O, Guerassimov A, Mehaoua A, Marcus A, and Furht B. 2014. Anomaly detection in medical wireless sensor networks using SVM and linear regression models. International Journal of EHealth and Medical Communications (IJEHMC) 5:20-45.

Santagati GE, Dave N, and Melodia T. 2020. Design and Performance Evaluation of an Implantable Ultrasonic Networking Platform for the Internet of Medical Things. IEEE/ACM Transactions on Networking 28:29-42. 10.1109/TNET.2019.2949805

Schneble W, and Thamilarasu G. 2019a. Attack Detection Using Federated Learning in Medical CyberPhysical Systems.

Schneble W, and Thamilarasu G. 2019b. Attack Detection Using Federated Learning in Medical CyberPhysical Systems. IEEE

Schneble W, and Thamilarasu G. 2019c. Optimal Feature Selection for Intrusion Detection in Medical Cyber-Physical Systems. 2019 11th International Conference on Advanced Computing (ICOAC): IEEE. p 238-243.

Sehatbakhsh N, Alam M, Nazari A, Zajic A, and Prvulovic M. 2018. Syndrome: Spectral analysis for anomaly detection on medical iot and embedded devices. 2018 IEEE international symposium on hardware oriented security and trust (HOST): IEEE. p 1-8.

Sethi P, and Sarangi SR. 2017. Internet of things: architectures, protocols, and applications. Journal of Electrical and Computer Engineering 2017.

Shafiq M, Tian Z, Bashir AK, Du X, and Guizani M. 2020. IoT malicious traffic identification using wrapperbased feature selection mechanisms. Computers \& Security:101863.

Shakeel PM, Baskar S, Dhulipala VS, Mishra S, and Jaber MM. 2018. Maintaining security and privacy in health care system using learning based deep-Q-networks. Journal of medical systems 42:186.

Shang J, and Wu J. 2019. A Usable Authentication System Using Wrist-worn Photoplethysmography Sensors on Smartwatches. 2019 IEEE Conference on Communications and Network Security (CNS): IEEE. p 1-9.

Peer] Comput. Sci. reviewing PDF | (CS-2020:10:53665:1:1:NEW 19 Jan 2021) 
1201

1202

1203

1204

1205

1206

1207

1208

1209

1210

1211

1212

1213

1214

1215

1216

1217

1218

1219

1220

1221

1222

1223

1224

1225

1226

1227

1228

1229

1230

1231

1232

1233

1234

1235

1236

1237

1238

1239

1240

1241

1242

1243

1244

1245

1246

1247
Shen J, Chang S, Shen J, Liu Q, and Sun X. 2018. A lightweight multi-layer authentication protocol for wireless body area networks. Future Generation Computer Systems 78:956-963.

https://doi.org/10.1016/j.future.2016.11.033

Sollins KR. 2018. IoT Big Data Security and Privacy vs. Innovation. IEEE Internet Things J.

Spiekermann S. 2015. Ethical IT innovation: A value-based system design approach: CRC Press.

Stiawan D, Idris M, Malik RF, Nurmaini S, Alsharif N, and Budiarto R. 2019. Investigating Brute Force Attack Patterns in loT Network. Journal of Electrical and Computer Engineering 2019.

Sun Y, Lo FP-W, and Lo B. 2019. Security and Privacy for the Internet of Medical Things Enabled Healthcare Systems: A Survey. IEEE Access 7:183339-183355.

Tahsien SM, Karimipour H, and Spachos P. 2020. Machine learning based solutions for security of Internet of Things (IoT): A survey. Journal of Network and Computer Applications:102630.

Thamilarasu G. 2016. iDetect: an intelligent intrusion detection system for wireless body area networks. International Journal of Security and Networks 11:82-93.

Tovino SA. 2016. The HIPAA Privacy Rule and the EU GDPR: illustrative comparisons. Seton Hall L Rev 47:973.

Tseng TW, Wu CT, and Lai F. 2019. Threat Analysis for Wearable Health Devices and Environment Monitoring Internet of Things Integration System. IEEE Access 7:144983-144994. 10.1109/ACCESS.2019.2946081

Verner A, and Butvinik D. 2017. A machine learning approach to detecting sensor data modification intrusions in WBANs. 2017 16th IEEE International Conference on Machine Learning and Applications (ICMLA): IEEE. p 161-169.

Vhaduri S, and Poellabauer C. 2019. Multi-modal biometric-based implicit authentication of wearable device users. IEEE Transactions on Information Forensics and Security 14:3116-3125.

Vinitha S, Sweetlin S, Vinusha H, and Sajini S. 2018. Disease prediction using machine learning over big data. Computer Science \& Engineering: An International Jouranl (CSEIJ) 8.

Wang Y, Meng W, Li W, Li J, Liu W-X, and Xiang Y. 2018. A fog-based privacy-preserving approach for distributed signature-based intrusion detection. Journal of Parallel and Distributed Computing 122:26-35.

Wazid M, Das AK, Rodrigues J, Shetty S, and Park Y. 2019a. IoMT Malware Detection Approaches: Analysis and Research Challenges. IEEE Access 7:182459-182476. 10.1109/access.2019.2960412

Wazid M, Das AK, Rodrigues JJ, Shetty S, and Park Y. 2019b. IoMT malware detection approaches: Analysis and research challenges. IEEE Access 7:182459-182476.

Weyrich M, and Ebert C. 2015. Reference architectures for the internet of things. IEEE Software 33:112116.

Wolfgang E. 2011. Introduction to artificial intelligence. Translated by Nathanael Black With illustrations by Florian Mast, Springer-Verlag London Limited.

Wu F, Li X, Sangaiah AK, Xu L, Kumari S, Wu L, and Shen J. 2018. A lightweight and robust two-factor authentication scheme for personalized healthcare systems using wireless medical sensor networks. Future Generation Computer Systems 82:727-737. https://doi.org/10.1016/i.future.2017.08.042

Xiao L, Wan X, Lu X, Zhang Y, and Wu D. 2018. IoT security techniques based on machine learning: How do loT devices use Al to enhance security? IEEE Signal Processing Magazine 35:41-49.

Xing K, Srinivasan SSR, Jose M, Li J, and Cheng X. 2010. Attacks and countermeasures in sensor networks: a survey. Network security: Springer, 251-272.

Xu G, Lan Y, Zhou W, Huang C, Li W, Zhang W, Zhang G, Ng EYK, Cheng Y, Peng Y, and Che W. 2019. An IoT-Based Framework of Webvr Visualization for Medical Big Data in Connected Health. IEEE Access 7:173866-173874. 10.1109/ACCESS.2019.2957149

Peer] Comput. Sci. reviewing PDF | (CS-2020:10:53665:1:1:NEW 19 Jan 2021) 
1248

1249

1250

1251

1252

1253

1254

1255

1256

1257

1258

1259

1260

1261

1262

1263

1264

1265

1266

1267

1268

1269

1270
Xu J, Wei L, Wu W, Wang A, Zhang Y, and Zhou F. 2020. Privacy-preserving data integrity verification by using lightweight streaming authenticated data structures for healthcare cyber-physical system. Future Generation Computer Systems 108:1287-1296. https://doi.org/10.1016/j.future.2018.04.018

Yaacoub J-PA, Noura M, Noura HN, Salman O, Yaacoub E, Couturier R, and Chehab A. 2020. Securing internet of medical things systems: Limitations, issues and recommendations. Future Generation Computer Systems 105:581-606. https://doi.org/10.1016/i.future.2019.12.028

Yang Y, Zheng X, Guo W, Liu X, and Chang V. 2018. Privacy-preserving fusion of loT and big data for ehealth. Future Generation Computer Systems 86:1437-1455. https://doi.org/10.1016/j.future.2018.01.003

Yeh K-H. 2016. BSNCare+: A robust loT-oriented healthcare system with non-repudiation transactions. Applied Sciences 6:418.

Zhang M, Raghunathan A, and Jha NK. 2013. MedMon: Securing medical devices through wireless monitoring and anomaly detection. IEEE Transactions on Biomedical circuits and Systems 7:871881.

Zhang Y, Gravina R, Lu H, Villari M, and Fortino G. 2018. PEA: Parallel electrocardiogram-based authentication for smart healthcare systems. Journal of Network and Computer Applications 117:10-16. 
Figure 1

Figure 1: The keywords used in the Research Information Template (RIT).

The entire Mind Map show The keywords used in the Research Information Template (RIT).

The rectangle box at the middle represent the main keywords, then the square boxes

represent the derived similar words from the main words. The oval shaped keywords are dervied from their previous sequare box keywords

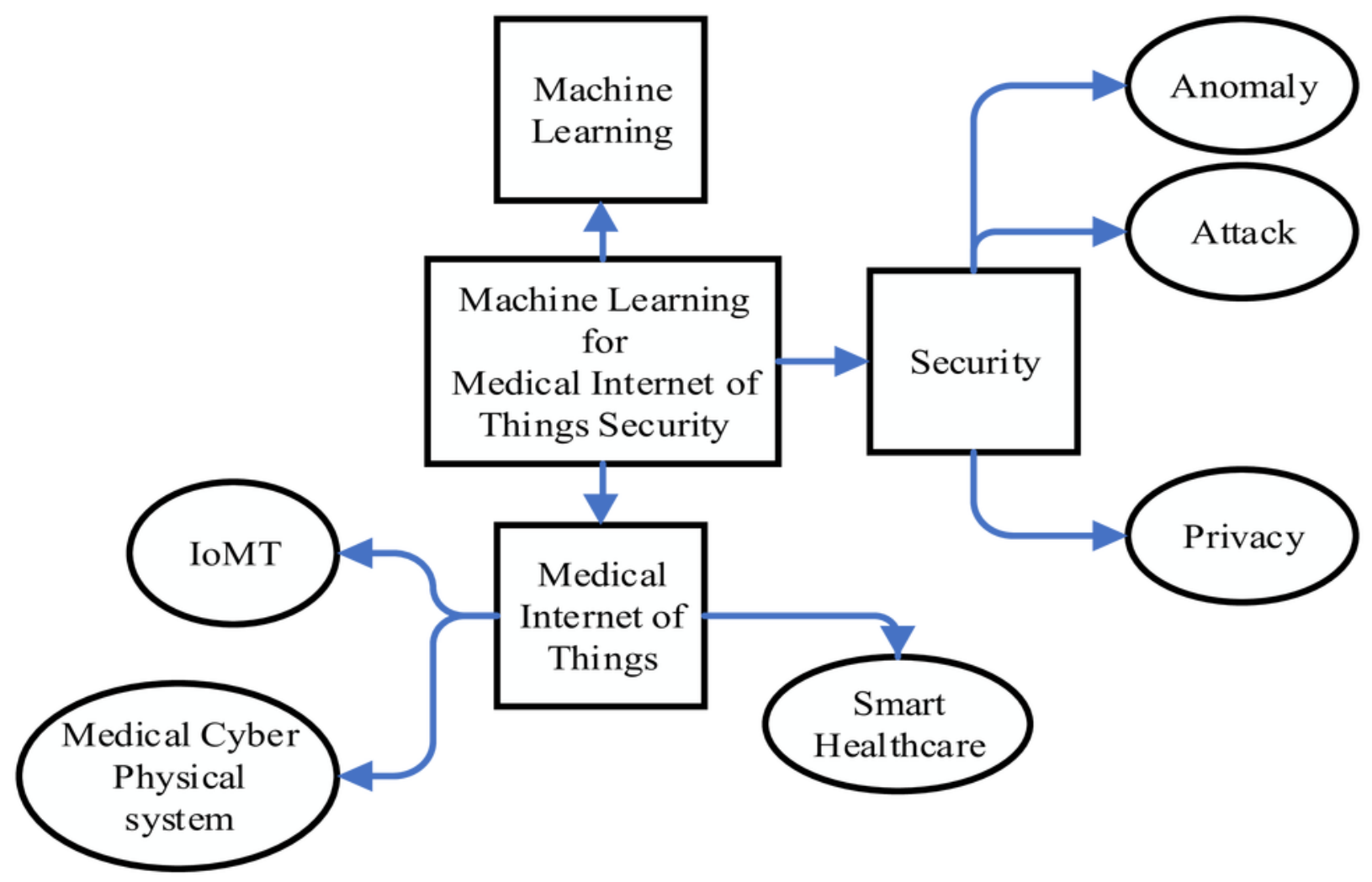




\section{Figure 2}

Figure 2: The search strategy used for selecting the research papers based on the PRISMA guideline.

The flow chart represents the procedure of searching in different databases using PRISMA guideline. It starts from top to bottom showing each step of paper selection and fileteration . 


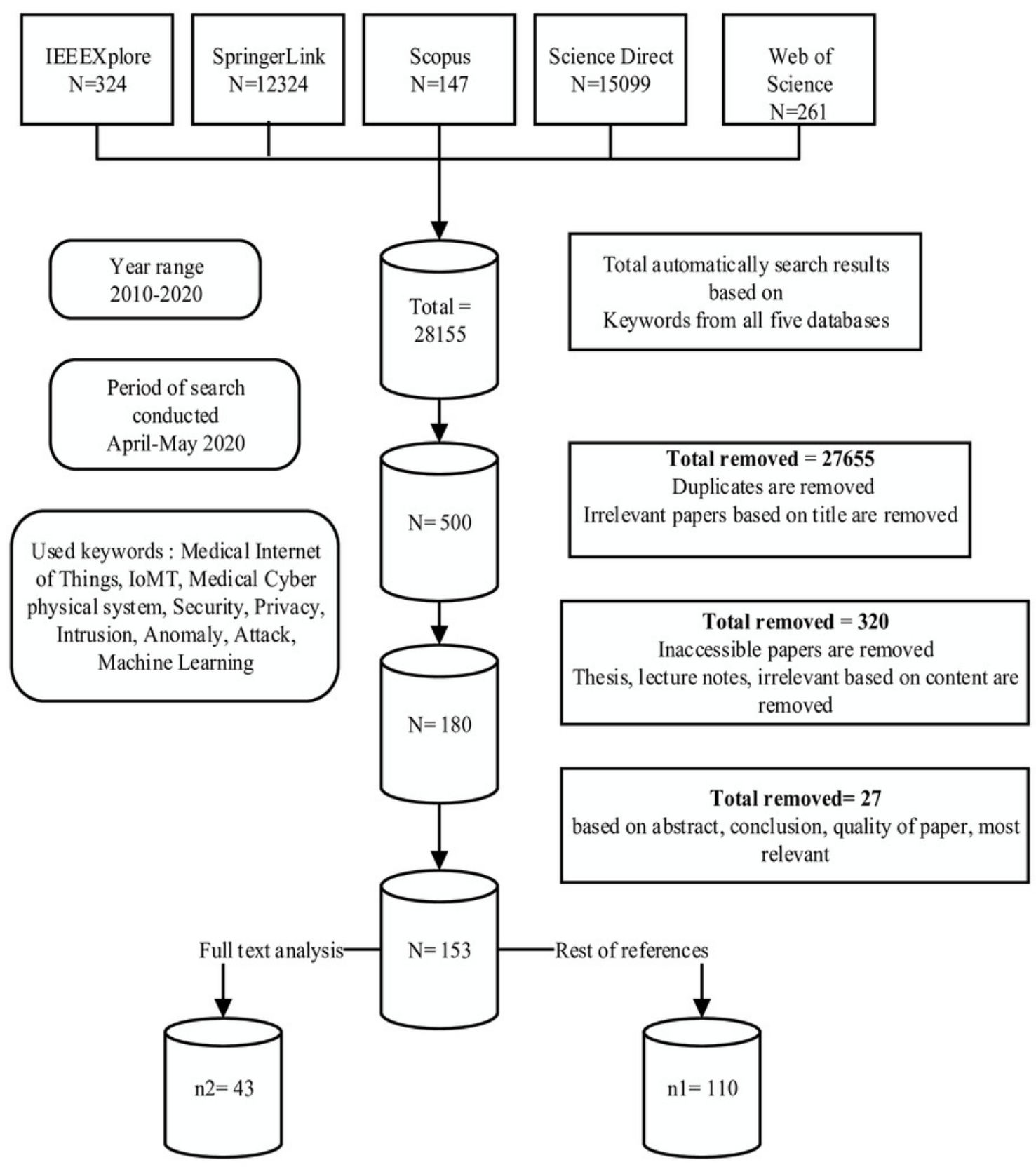




\section{Figure 3}

Figure 3: Geographical distribution of the papers.

The pie chart shows the percentage of the papers by each country

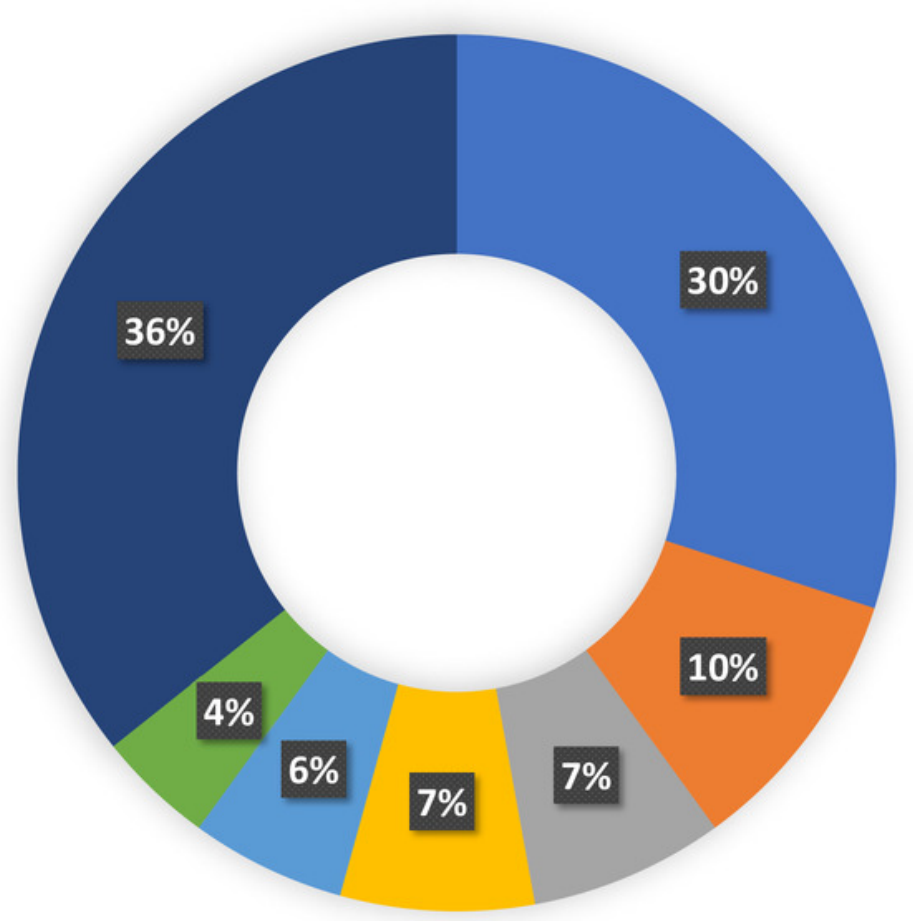

USA

India

Australia

Qatar

- Saudi Arabia

China

- Total others 
Figure 4

Figure 4: Distribution of the papers by year.

Each Blue Bar represent the number of papers published in each year and orange line shows the percentage of the included reviewed papers in each single year

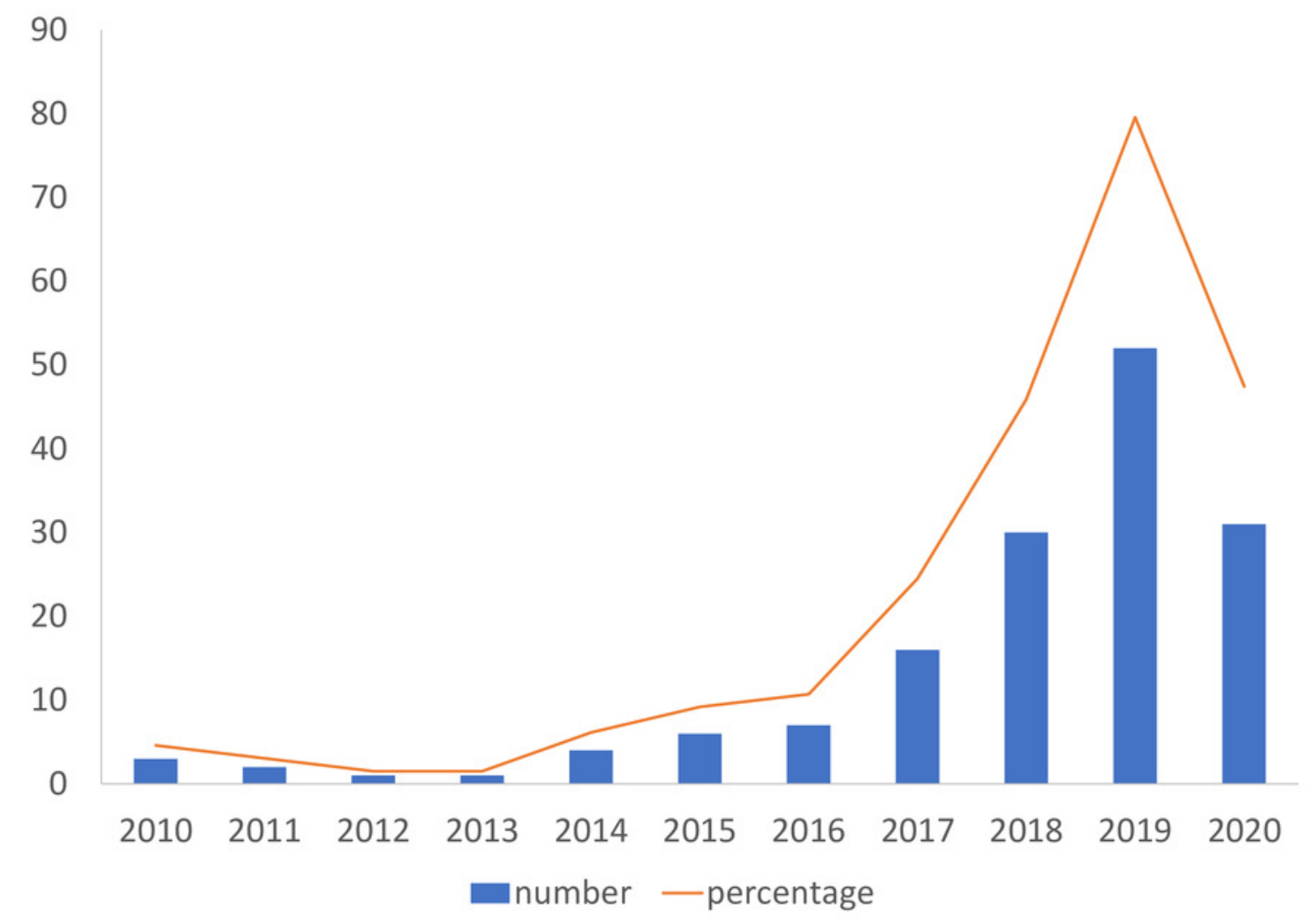




\section{Figure 5}

Figure 5: The type of analyzed papers used in the current research.

The pie chart shows the percentage of the analyzed papers in each catgory of Journal, Conference, and Book chapter

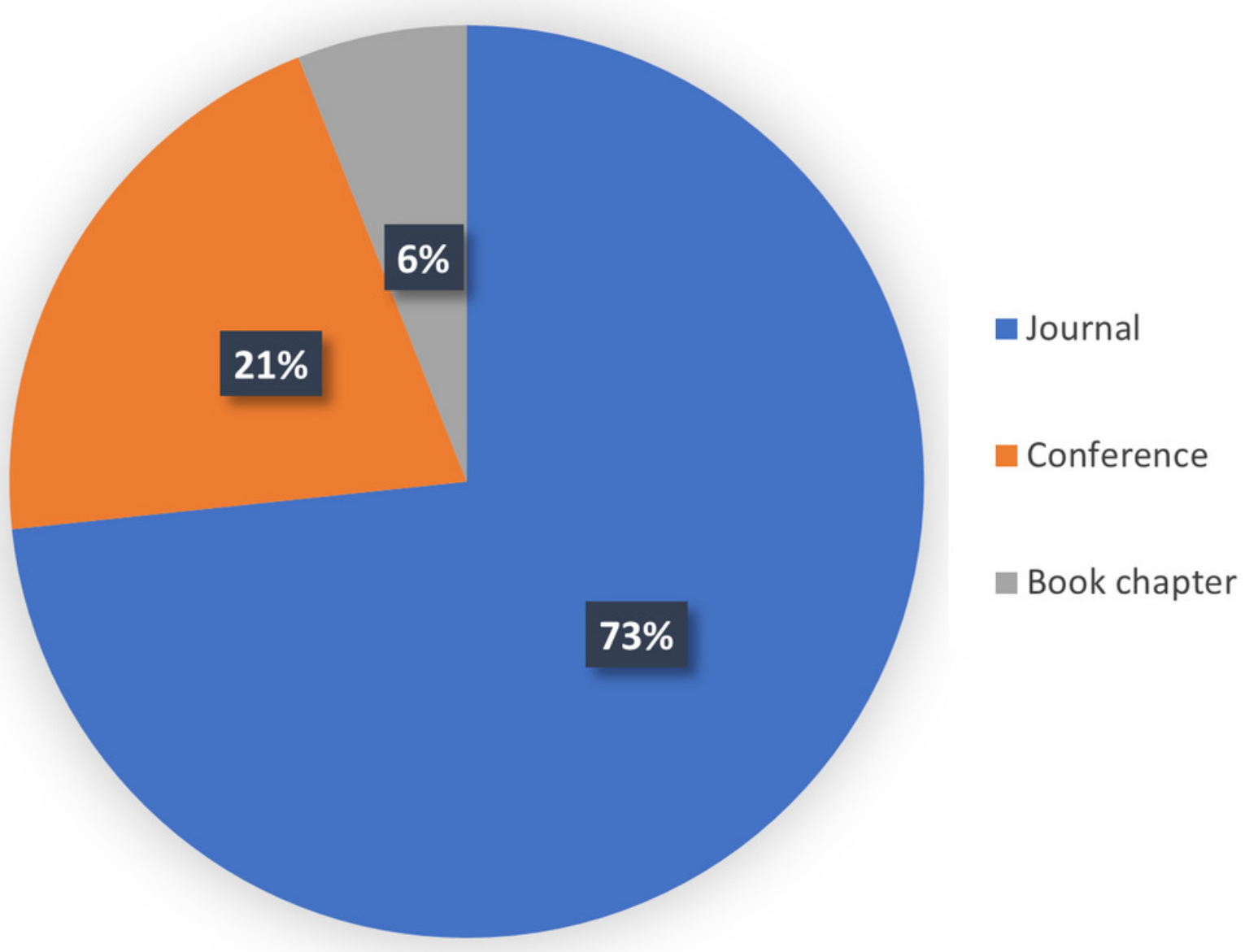




\section{Figure 6}

Figure 6: Distribution of the papers according to the publishers.

the pie chart line chart shows the percentage of the analyzed papers which are published by each publisher

percent

70

60

50

40

30

20

10

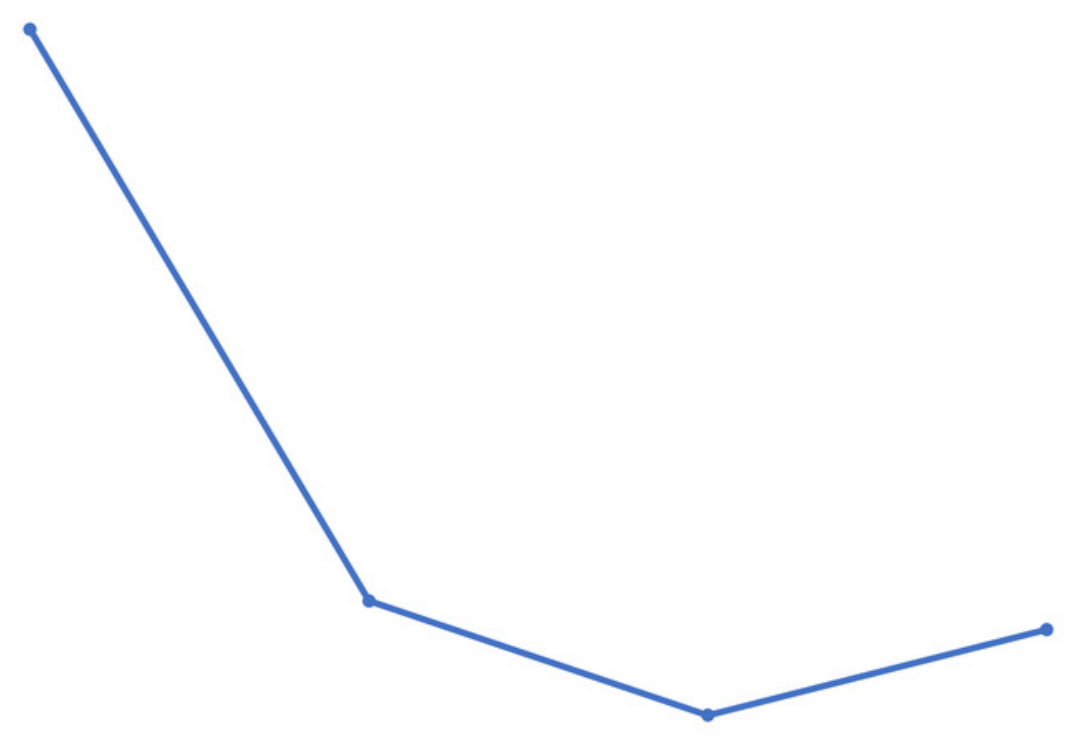

0

IEEE Elsevier Springer others




\section{Figure 7}

Figure 7: Papers distribution by the direction and problem-solving domain.

The pie chart show the direction of studies. The percentage of the papers for each direction of study is given in the chart

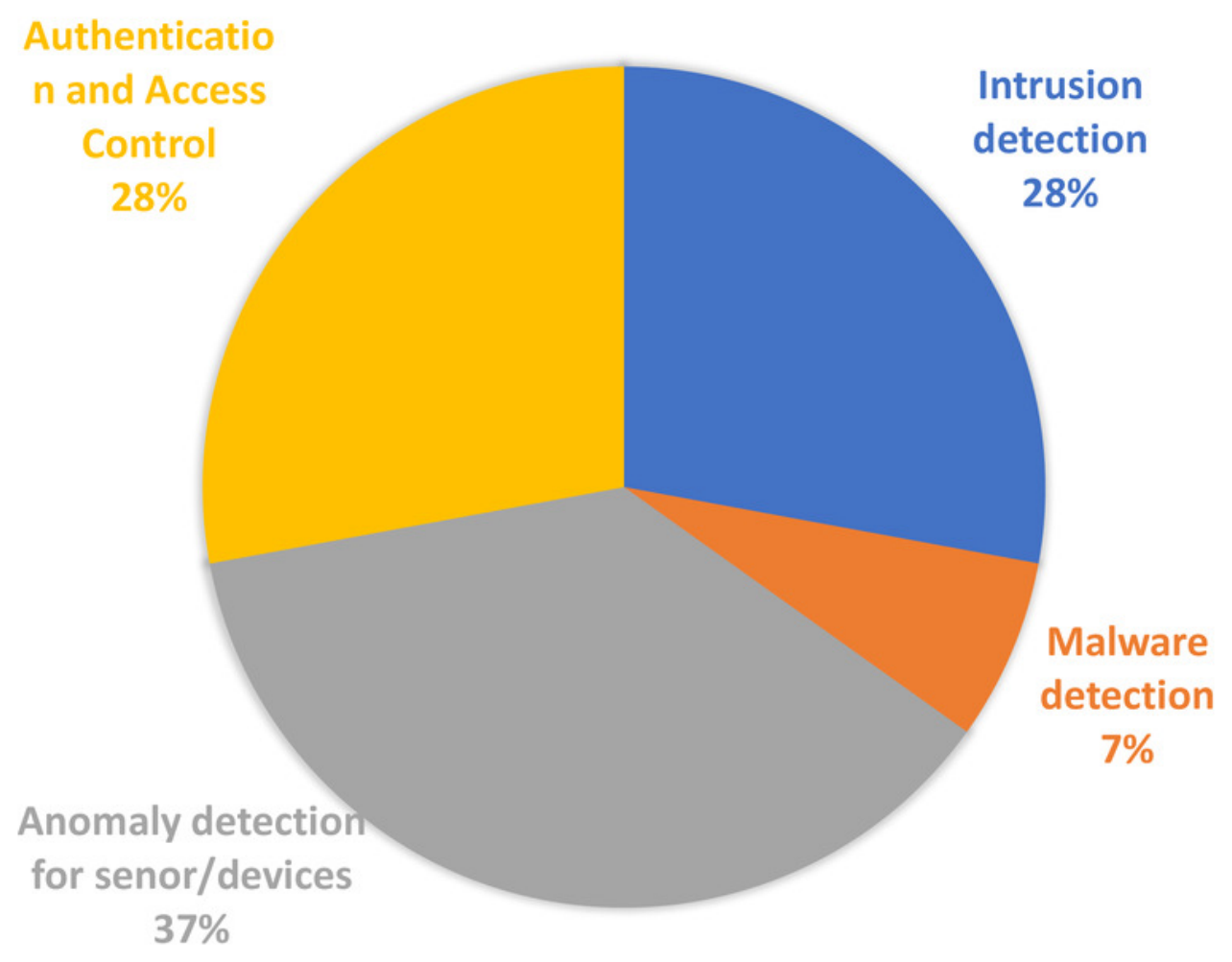




\section{Figure 8}

Figure 8. The type of data used by the researchers to conduct their research.

The pie chart shows the percentage of the papers in terms of the type of the data used for their analysis

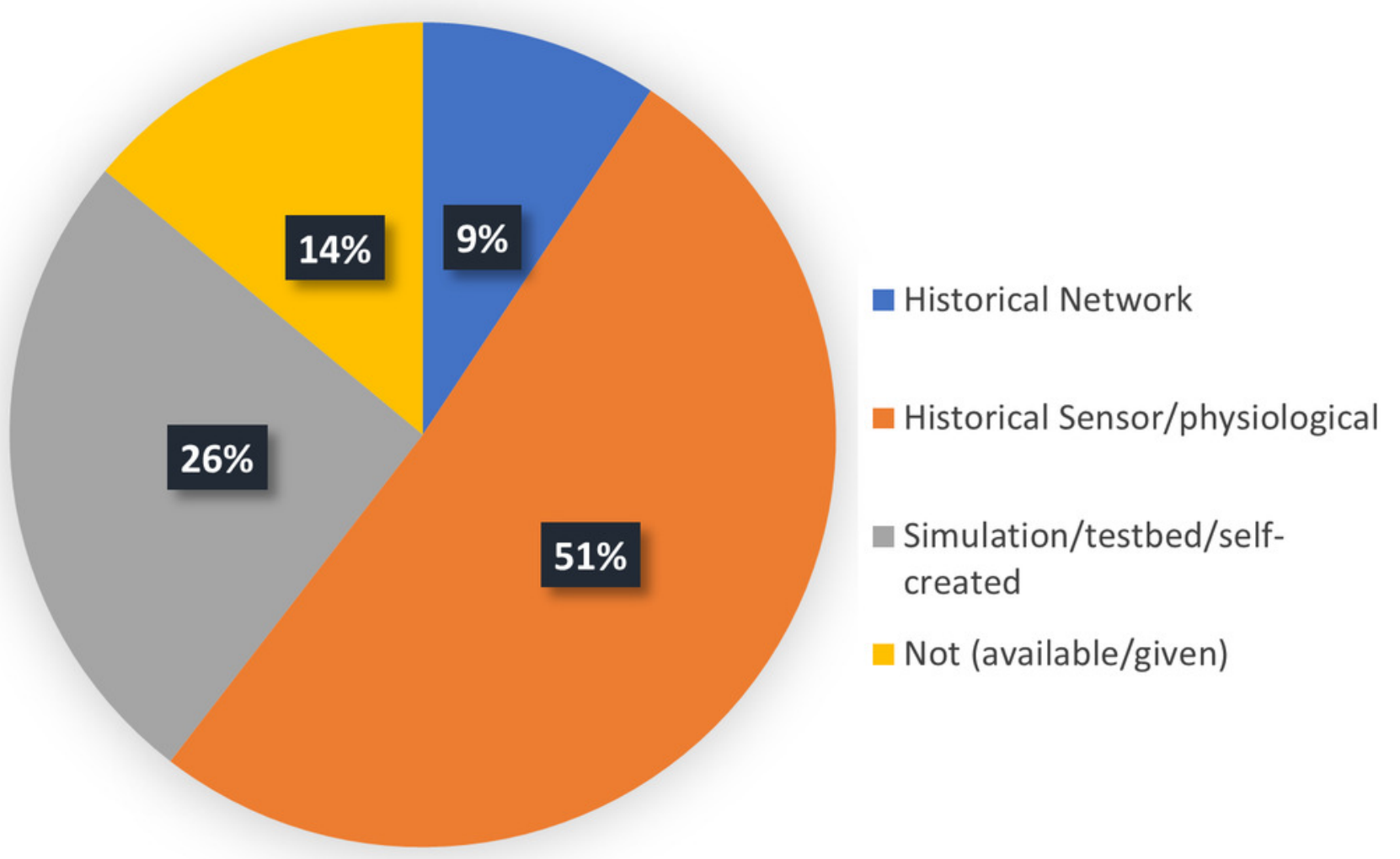




\section{Figure 9}

Figure 9: Software and tools used by the studies.

The pie chart shows the percentage of different tools and software which are used by the reviewed studies

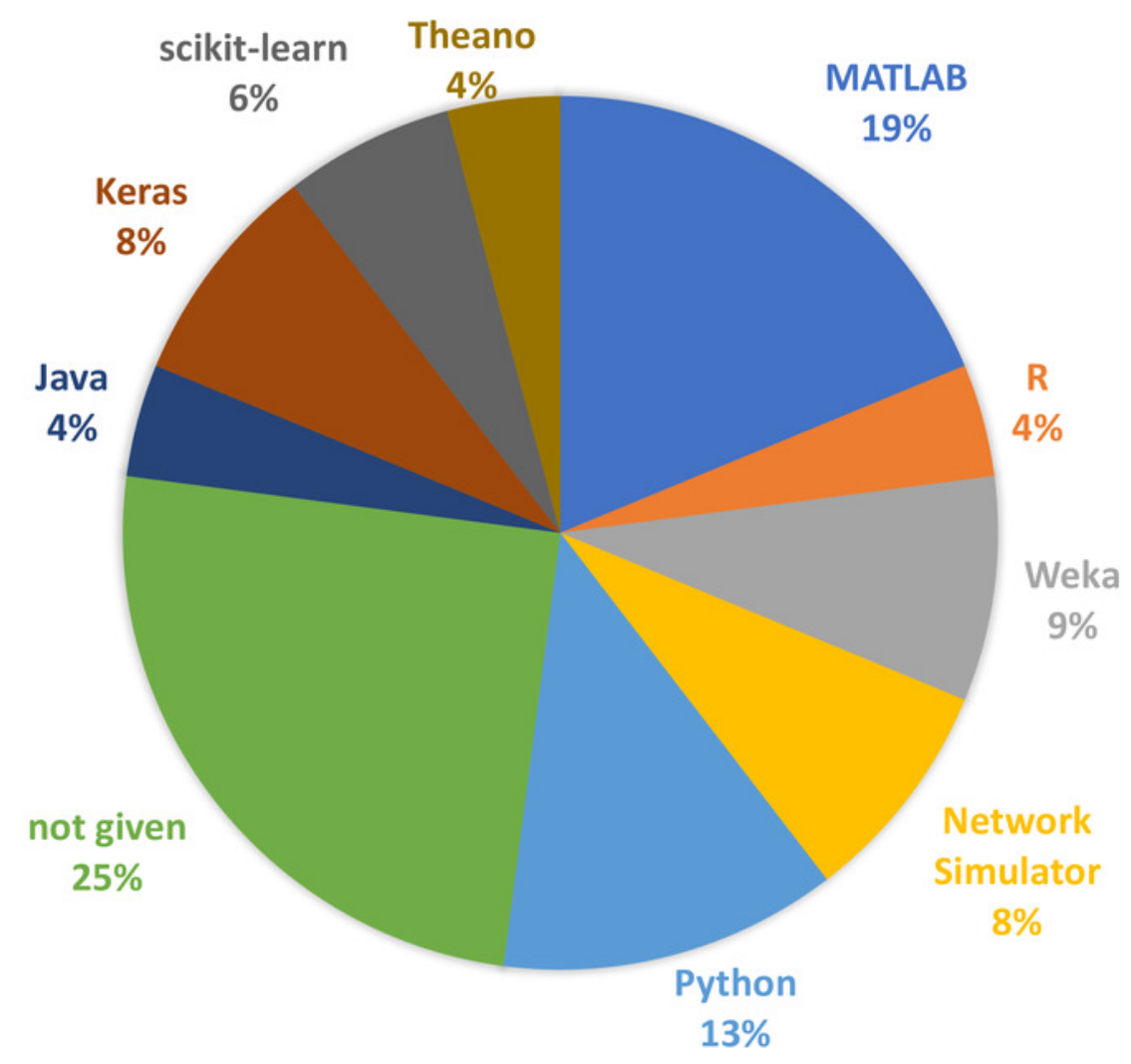




\section{Figure 10}

Figure 10: Devices and hardware tools used in the studies.

The bar chart shows the number of hardware tools used by the analyzed studies .

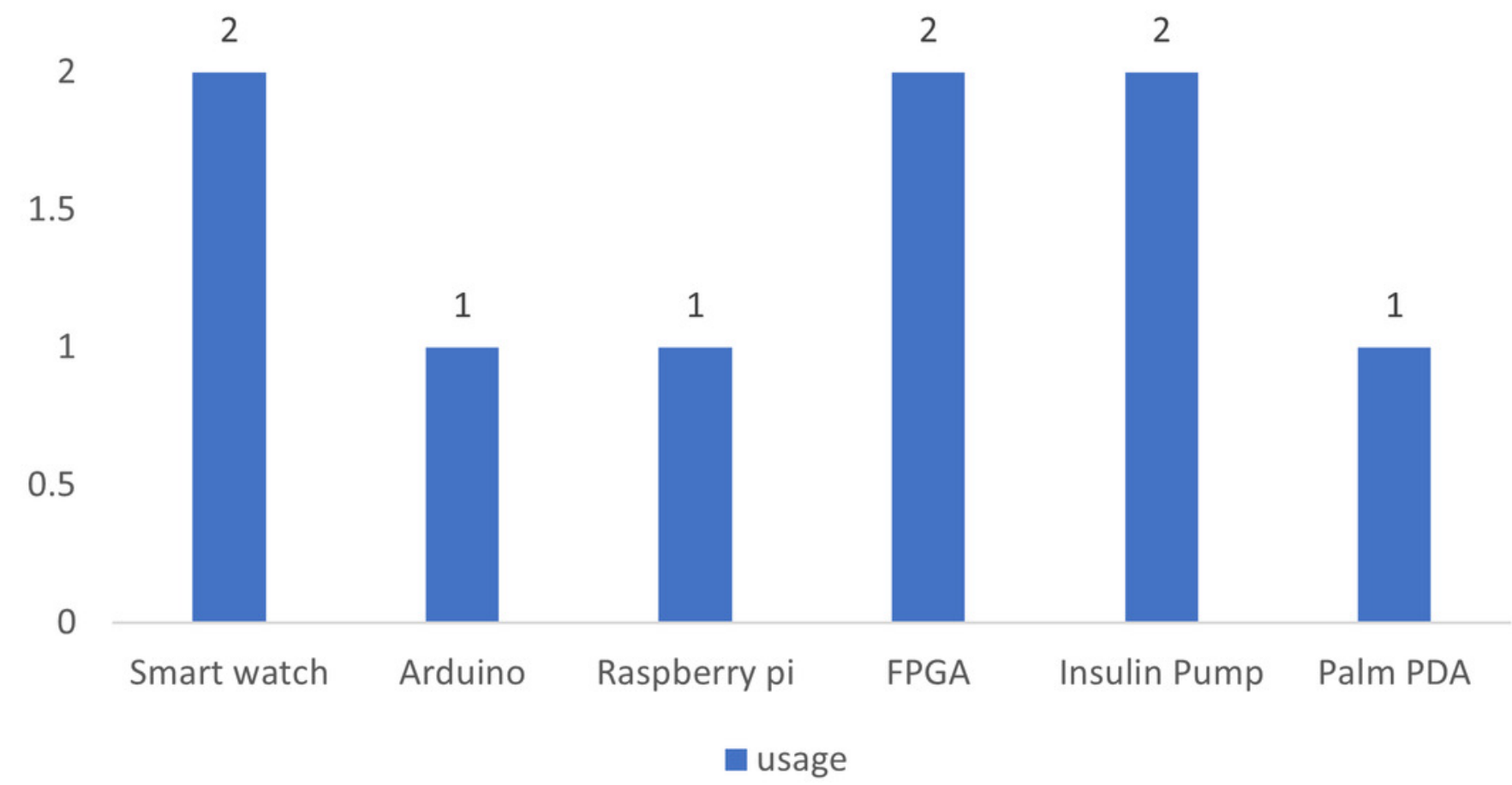




\section{Figure 11}

Figure 11: Analysis of the studies in terms of (a)complexity and (b) real time analysis

The pie chart ( a ) shows the percentage of the papers in terms of complexity \{lightweight, heavy, low complex The pie chart (b) shows the percentage of the analyzed papers based on their real time feature real time, not real time (heavy), low time complex)\}

a

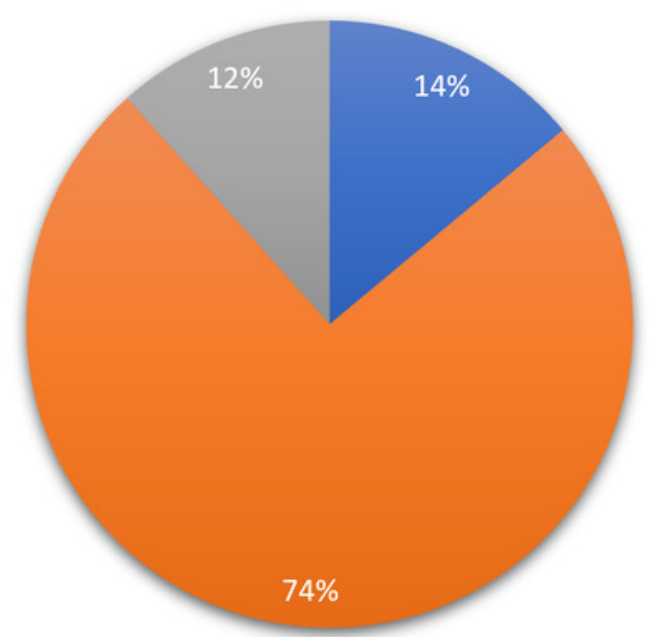

घ lightweight anot lightweight a low complexity b

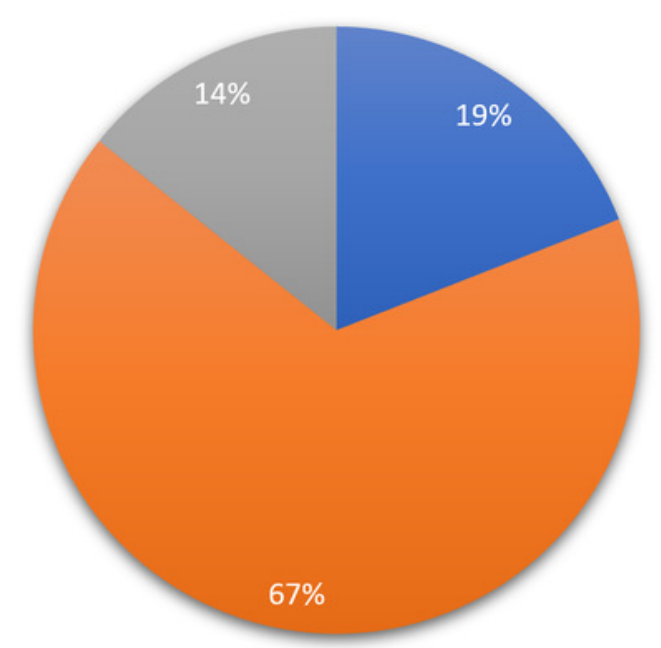

areal time

- low time complexity 


\section{Figure 12}

Figure 12: Details of the studies in terms of placement.

the chart shows the percentage of the papers based on their placement

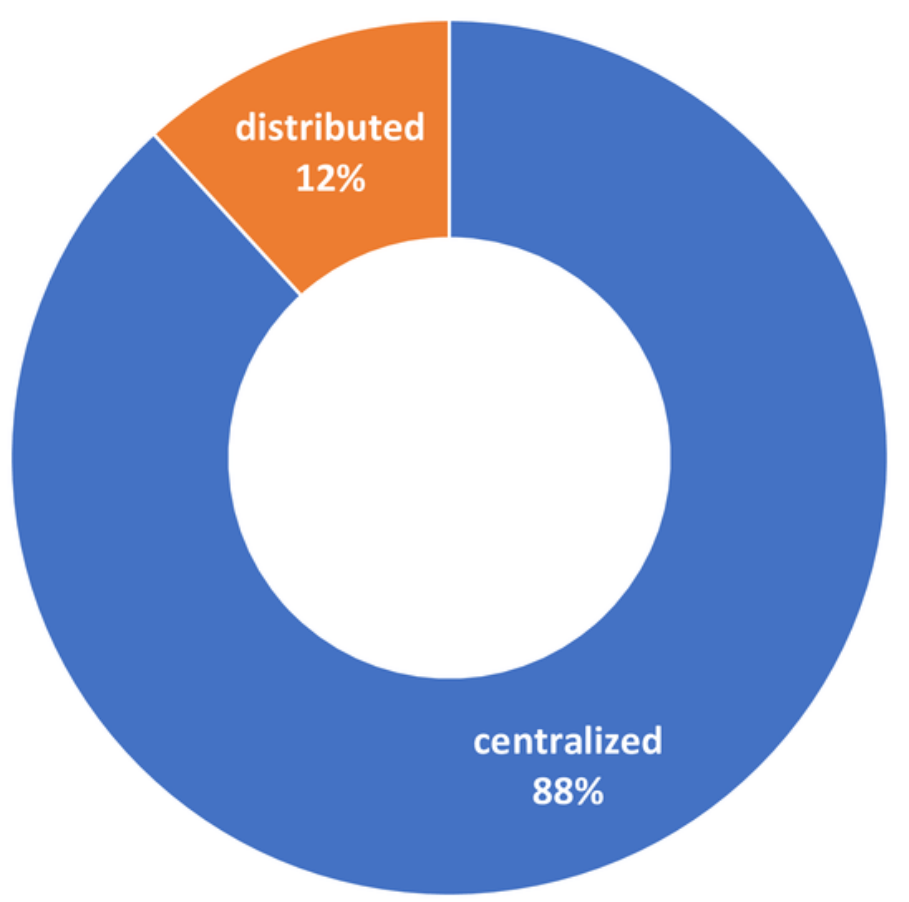




\section{Table $\mathbf{1}$ (on next page)}

Table 1: The types and characteristics of medical devices used in the loMT system.

Each row represent different type of medical device and each column represents characteristic of that device 
1 Table 1:

2 The types and characteristics of medical devices used in the IoMT system.

\begin{tabular}{|c|c|c|c|c|}
\hline Device type & Placement & Example & $\begin{array}{l}\text { Risk } \\
\text { Value }\end{array}$ & Ref. \\
\hline Implantable & $\mathrm{H}$ Within the human tissues & $\begin{array}{l}\text { deep brain implants, heart } \\
\text { pacemaker and insulin } \\
\text { pump }\end{array}$ & High & $\begin{array}{l}\text { (Santagati et al. } \\
\text { 2020) }\end{array}$ \\
\hline Wearable & On the human body & $\begin{array}{l}\text { smart watches, fitness } \\
\text { devices }\end{array}$ & Low & $\begin{array}{l}\text { (Tseng et al. } \\
\text { 2019) }\end{array}$ \\
\hline Ambient & Outside the human body & $\begin{array}{l}\text { elderly monitoring } \\
\text { devices in smart home }\end{array}$ & Low & $\begin{array}{l}\text { (Pandey \& } \\
\text { Litoriya 2020) }\end{array}$ \\
\hline Stationary & Inside hospitals & $\begin{array}{l}\text { medical image processing } \\
\text { devices of MRI and CT- } \\
\text { Scan }\end{array}$ & Low & $\begin{array}{l}\text { (Nanayakkara } \\
\text { et al. 2019; Xu } \\
\text { et al. 2019) }\end{array}$ \\
\hline
\end{tabular}

3

4

5

6

7

8

9

10

11

12

13 


\section{Table 2 (on next page)}

Table 2: Attacks on different the loMT layers with their respective impact on security requirements

Each row reprsenst different type of attack and the rows show their targeted layer, Impact, and Refrenece 
1 Table 2:

2 Attacks on different the IoMT layers with their respective impact on security requirements.

\begin{tabular}{|c|c|c|}
\hline Attacks & Impact & Ref. \\
\hline \multicolumn{3}{|l|}{ Targeted layer: Server/Database layer } \\
\hline Malware attack & Integrity, Availability & (Wazid et al. 2019) \\
\hline Ransomware attack & Integrity, Availability & (Fernandez Maimo et al. 2019) \\
\hline SQL injection & All & (Li et al. 2019, Gupta et al. 2020) \\
\hline $\begin{array}{l}\text { Social Engineering (Reverse } \\
\text { Engineering, Shoulder-surfing) }\end{array}$ & All & (Yaacoub et al. 2020) (Patel 2020) (He et al. 2018) \\
\hline Brute Force & Confidentiality, Integrity & (Stiawan et al. 2019) \\
\hline $\begin{array}{l}\text { Adversarial Machine Learning attacks } \\
\text { (Causative (Poisoning and Evasion } \\
\text { attacks), Exploratory) }\end{array}$ & Confidentiality, Integrity & $\begin{array}{l}\text { (Ibitoye, Shafiq and Matrawy 2019), (Mozaffari-Kermani } \\
\text { et al. 2014, Mosenia and Jha 2016), (Chakraborty et al. } \\
\text { 2018) }\end{array}$ \\
\hline \multicolumn{3}{|l|}{ Targeted layer: Network layer } \\
\hline $\begin{array}{l}\text { Denial of Service (DoS) and } \\
\text { Distributed DoS (DDoS) }\end{array}$ & All & $\begin{array}{l}\text { (Gupta et al. 2020, Yaacoub et al. 2020), (Al Shorman, } \\
\text { Faris and Aljarah 2019) }\end{array}$ \\
\hline Man in the Middle (MIM) attack & Confidentiality, Integrity & (Yaacoub et al. 2020) \\
\hline Eavesdropping attack & Confidentiality, Non-repudiation, Privacy & (Gupta et al. 2020) (McMahon et al. 2017) \\
\hline Replay attack & Confidentiality, Integrity & (Spiekermann 2015, Yaacoub et al. 2020) \\
\hline botnet attack & Availability, Confidentiality & (Bahşi, Nõmm and La Torre 2018) \\
\hline Mirai attack & Availability, Confidentiality & \\
\hline Jamming & Availability & (Sun, Lo and Lo 2019) \\
\hline flooding & Availability & $\begin{array}{l}\text { (Gupta et al. 2020, Shafiq et al. 2020, Yaacoub et al. } \\
\text { 2020) }\end{array}$ \\
\hline Packet Analysis attacks & $\begin{array}{l}\text { Integrity, Confidentiality, Non- } \\
\text { repudiation, Privacy }\end{array}$ & (Tseng, Wu and Lai 2019) \\
\hline \multicolumn{3}{|l|}{ Targeted layer: Device/sensor layer } \\
\hline Physical Sensor/ Node tampering & All & (Xing et al. 2010) \\
\hline False data Injection & $\begin{array}{l}\text { Integrity, Confidentiality, Non- } \\
\text { repudiation, Privacy }\end{array}$ & $\begin{array}{l}\text { (Rahman and Mohsenian-Rad 2012, Bostami, Ahmed and } \\
\text { Choudhury 2019, Farroha 2019, Newaz et al. 2020) }\end{array}$ \\
\hline $\begin{array}{l}\text { Resource Depletion Attacks (Battery } \\
\text { drain, Sleep deprivation, Buffer } \\
\text { overflow) }\end{array}$ & Availability & $\begin{array}{l}\text { (Hei et al. 2010), (Mosenia and Jha 2016), (Gupta et al. } \\
\text { 2020) }\end{array}$ \\
\hline Side-channel & Confidentiality, Non-repudiation, Privacy & (Zhang, Raghunathan and Jha 2013, Newaz et al. 2020) \\
\hline Hardware Trojan & All & (Qu and Yuan 2014, Mosenia and Jha 2016) \\
\hline Eavesdropping & Confidentiality, Non-repudiation, Privacy & (Gupta et al. 2020) (McMahon et al. 2017) \\
\hline
\end{tabular}




\section{Table 3(on next page)}

Table 3: The evaluation metrics used for ML techniques.

Each row represents a metric and the columns show their description, and formula 
1 Table 3:

2 The evaluation metrics used for ML techniques.

\begin{tabular}{|l|l|l|}
\hline Metric & Description & Formula \\
\hline Accuracy & Determines the performance of the model in recognizing all classes, respectively & Acc $=\frac{T P+T N}{N}$ \\
\hline $\begin{array}{l}\text { Sensitivity } \\
\text { Recall) }\end{array}$ & $\begin{array}{l}\text { Measures the completeness, which is the percentage of positive predicted samples } \\
\text { to the positive samples in dataset is depicted. }\end{array}$ & Sensitivity $=\frac{T P}{T P+F N}$ \\
\hline $\begin{array}{l}\text { Specificity } \\
\text { (Precision) }\end{array}$ & $\begin{array}{l}\text { Shows the exactness, in which the percentage of correctly positive predictive } \\
\text { samples to all positive predictive samples by the model are calculated. }\end{array}$ & Specificity $=\frac{T P}{T P+F P}$ \\
\hline $\begin{array}{l}\text { False Positive } \\
\text { Rate (FPR) }\end{array}$ & $\begin{array}{l}\text { Measures the number of those normal network behaviors which are calculated as } \\
\text { attack. }\end{array}$ & FPR $=F P /($ FP $+T N)$ \\
\hline $\begin{array}{l}\text { Performance } \\
\text { overhead }\end{array}$ & $\begin{array}{l}\text { It is the calculation of any combination of (memory, CPU, energy) overhead taken } \\
\text { by the ML techniques to perform a task. }\end{array}$ & $\begin{array}{l}\text { Big(o)notation for time and } \\
\text { space complexity and Energy } \\
\text { unit for energy usage }\end{array}$ \\
\hline \multicolumn{2}{|l|}{\begin{tabular}{l} 
Where TP is True Positive, TN is True Negative, N is total number of samples, FP is False Negative FP is False Positive \\
\hline
\end{tabular}}
\end{tabular}

\section{4}




\section{Table 4 (on next page)}

Table 4: Comparison between this survey and other related surveys.

Each row show different related study and columns show their features 
1 Table 4:

2 Comparison between this survey and other related surveys.

\begin{tabular}{|c|c|c|c|c|c|c|c|c|}
\hline Year & Ref. & $\begin{array}{l}\text { IoT } \\
\text { domain }\end{array}$ & Architecture & Threats & $\begin{array}{l}\text { ML } \\
\text { methods }\end{array}$ & Big data & $\begin{array}{l}\text { ML for } \\
\text { IoMT } \\
\text { security }\end{array}$ & $\begin{array}{l}\text { Systematic } \\
\text { analysis }\end{array}$ \\
\hline 2018 & $\begin{array}{l}\text { (Cui et al. } \\
2018 \text { ) }\end{array}$ & Generic & NA & NA & Discussed & NA & NA & NA \\
\hline 2020 & $\begin{array}{l}\text { (Tahsien et } \\
\text { al. 2020) }\end{array}$ & Generic & $\begin{array}{l}\text { IoT } \\
\text { architecture }\end{array}$ & IoT attacks & Discussed & NA & NA & NA \\
\hline 2020 & $\begin{array}{l}\text { (Hussain et } \\
\text { al. 2020) }\end{array}$ & Generic & NA & IoT attacks & Discussed & $\begin{array}{l}\text { Big data at } \\
\text { cloud }\end{array}$ & NA & NA \\
\hline 2019 & $\begin{array}{l}\text { (Sun et al. } \\
2019 \text { ) }\end{array}$ & IoMT & $\begin{array}{l}\text { IoMT } \\
\text { architecture }\end{array}$ & $\begin{array}{l}\text { IoMT } \\
\text { Security } \\
\text { requirement }\end{array}$ & NA & NA & $\begin{array}{l}\text { Partially } \\
\text { discussed }\end{array}$ & NA \\
\hline 2020 & $\begin{array}{l}\text { (Newaz et al. } \\
2020 \text { ) }\end{array}$ & IoMT & $\begin{array}{l}\text { IoMT } \\
\text { architecture }\end{array}$ & IoMT attacks & NA & NA & $\begin{array}{l}\text { Partially } \\
\text { discussed }\end{array}$ & NA \\
\hline 2020 & $\begin{array}{l}\text { (Yaacoub et } \\
\text { al. 2020) }\end{array}$ & IoMT & $\begin{array}{l}\text { IoMT } \\
\text { architecture }\end{array}$ & IoT attacks & NA & NA & NA & NA \\
\hline- & This study & IoMT & $\begin{array}{l}\text { IoMT } \\
\text { architecture }\end{array}$ & $\begin{array}{l}\text { IoMT } \\
\text { Attacks }\end{array}$ & Discussed & Discussed & Discussed & $\begin{array}{l}\text { Comprehensive } \\
\text { and Systematic } \\
\text { Review }\end{array}$ \\
\hline
\end{tabular}

3 


\section{Table 5 (on next page)}

Table 5: The searching queries and results achieved from five different databases.

Each row shows different queries used for all databases and the columns show their results 


\section{Table 5:}

\begin{tabular}{|c|c|c|c|c|c|}
\hline Searching texts versus databases & $\begin{array}{l}\text { IEEE } \\
\text { Xplore }\end{array}$ & $\begin{array}{l}\text { Springer } \\
\text { Link }\end{array}$ & Scopus & $\begin{array}{l}\text { Science } \\
\text { Direct }\end{array}$ & $\begin{array}{l}\text { Web of } \\
\text { Science }\end{array}$ \\
\hline Machine Learning AND Medical Internet of Things AND Security & 89 & 3431 & 63 & 2459 & 33 \\
\hline Machine Learning AND Medical Internet of Things AND Intrusion & 6 & 336 & 2 & 445 & 3 \\
\hline Machine Learning AND Medical Internet of Things AND Attack & 13 & 1225 & 2 & 1203 & 18 \\
\hline Machine Learning AND IoMT AND Security & 9 & 81 & 3 & 929 & 5 \\
\hline Machine Learning AND IoMT AND Attack & 0 & 33 & & 64 & 5 \\
\hline Machine Learning AND Medical Cyber Physical system AND Security & 30 & 481 & 5 & 1038 & 11 \\
\hline Machine Learning AND Medical Cyber Physical system AND Privacy & 8 & 429 & 3 & 693 & 4 \\
\hline $\begin{array}{l}\text { Machine Learning AND Medical Cyber Physical system AND } \\
\text { Intrusion }\end{array}$ & 6 & 321 & 3 & 301 & 4 \\
\hline Machine Learning AND Smart healthcare AND Intrusion & 7 & 334 & 1 & 431 & 21 \\
\hline Machine Learning AND Smart healthcare AND Attack & 20 & 1031 & 3 & 1209 & 20 \\
\hline Total including duplicates & 324 & 12324 & 147 & 15099 & 261 \\
\hline
\end{tabular}

2 The searching queries and results achieved from five different databases.

3 


\section{Table 6(on next page)}

Table 6: Selection criteria of the papers at final stage

each row represent a criadera for selecting the papers and the coloumn shows the responce 
1 Table 6:

2 Selection criteria of the papers at final stage

\begin{tabular}{|l|l|l|}
\hline Criteria\# & Questions & Answer \\
\hline 1 & Does the paper relevant to the topic? & Y/N \\
\hline 2 & $\begin{array}{l}\text { Does the work propose a machine learning related solution and } \\
\text { method to solve a problem in the IoMT security and/or } \\
\text { privacy? }\end{array}$ & $\mathrm{Y} / \mathrm{N}$ \\
\hline 3 & $\begin{array}{l}\text { Is the paper published in scholarly journals, conferences, } \\
\text { books? }\end{array}$ & $\mathrm{Y} / \mathrm{N}$ \\
\hline
\end{tabular}

3 


\section{Table 7 (on next page)}

Table 7: Classification of papers based on ML category, medical device, and the IoMT layer.

The table shows a matrix represntation of the paper's classification to different categories 
1 Table 7:

2 Classification of papers based on ML category, medical device, and the IoMT layer.

\begin{tabular}{|c|c|}
\hline ML category - medical device category & IoMT layer- Ref \\
\hline Supervised ML - Implantable, wearable & $\begin{array}{l}\text { Sensor layer- }\{\text { (Haque, Rahman and Aziz 2015),(Abdaoui et al. 2020) } \\
\text { (Rathore et al. 2018), (Khan et al. 2017), (Gao and Thamilarasu 2017), (Newaz } \\
\text { et al. 2019), (Ben Amor, Lahyani and Jmaiel 2020), (Mohamed, Meddeb- } \\
\text { Makhlouf and Fakhfakh 2019), (Salem et al. 2014), (Hau and Lupu 2019), } \\
\text { (Nagdeo and Mahapatro 2019), (Verner and Butvinik 2017) }\} \\
\text { All layers-(Rathore et al. 2018b) }\end{array}$ \\
\hline $\begin{array}{l}\text { Supervised ML- Wearable, smart watches, } \\
\text { smart fitness }\end{array}$ & $\begin{array}{l}\text { Device layer- }\{\text { (Pirbhulal et al. 2019), (Mawgoud et al. 2019), (Barros et al. } \\
\text { 2019), (Zhang et al. 2018), (Shang \& Wu 2019), (Musale et al. 2019), (Vhaduri } \\
\text { \& Poellabauer 2019), (Mohsen et al. 2019), (Rathore et al. 2018a) }\} \\
\text { Network layer- }\{(\text { Begli, Derakhshan and Karimipour 2019), (Itten and } \\
\text { Vadakkumcheril 2016), (Schneble and Thamilarasu 2019), (Odesile and } \\
\text { Thamilarasu 2017), (RM et al. 2020), (Asfaw et al. 2010), (Alrashdi et al. } \\
\text { 2019), (Wazid et al. 2019), (Fernandez Maimo et al. 2019)\} } \\
\text { Cloud layer- }\{\text { (Punithavathi et al. 2019), (Landau et al. 2020)\} }\end{array}$ \\
\hline Unsupervised ML-Implantable, wearable & $\begin{array}{l}\text { Sensor layer- }\{\text { (Ben Amor, Lahyani and Jmaiel 2020),(Sehatbakhsh et al. } \\
\text { 2018), (Zhang, Raghunathan and Jha 2013), (Verner and Butvinik 2017)\} }\end{array}$ \\
\hline Unsupervised ML-Wearable & $\begin{array}{l}\text { Device layer- }\{(\text { Zhang et al. 2018), (Shang \& Wu 2019), (Musale et al. 2019), } \\
\text { (Vhaduri \& Poellabauer 2019), (Mohsin et al. 2019)\} } \\
\text { Network layer- }\{(\text { Schneble and Thamilarasu 2019), (He et al. 2019),(RM et al. } \\
\text { 2020), (Thamilarasu 2016), Fernandez Maimo et al. 2019)\} }\end{array}$ \\
\hline Unsupervised ML-ICD, Programmer & Device layer- (Kintzlinger et al. 2020) \\
\hline Deep learning-Wearable & $\begin{array}{l}\text { Device layer-\{(RM et al. 2020), (Manimurugan et al. 2020), (Shakeel et al. } \\
\text { 2018), (Rathore et al. 2019), (Mohsin et al. 2019) }\}\end{array}$ \\
\hline Big data-Wearable & Device layer-(Zhang et al. 2018) \\
\hline
\end{tabular}




\section{Table 8(on next page)}

Table 8: Details of published studies on anomaly and attack detection to the sensors/medical devices

each row represent each paper under category anomaly and attack detection to the sensors/medical devices and the columns show their characteristics that are used for evaluating them 
2 Table 8:

3 Details of published studies on anomaly and attack detection to the sensors/medical devices

\begin{tabular}{|c|c|c|c|c|c|c|}
\hline Ref. & Methods & Detection type & Good features & Limitations & Tools & Dataset info. \\
\hline $\begin{array}{l}\text { (Haque, Rahman } \\
\text { and Aziz 2015) }\end{array}$ & SMO & Anomaly detection & $\begin{array}{l}\text { - high detection rate } \\
\text { - low FPR }\end{array}$ & $\begin{array}{l}\text { - high computation } \\
\text { overhead }\end{array}$ & Weka & $\begin{array}{l}-10 \text { real } \\
\text { datasets } \\
-(\text { MIMIC)data } \\
\end{array}$ \\
\hline $\begin{array}{l}\text { (Abdaoui et al. } \\
\text { 2020) }\end{array}$ & $\begin{array}{l}\text { Deep } \\
\text { Learning }\end{array}$ & $\begin{array}{l}\text { Anomaly based false } \\
\text { alarm detection }\end{array}$ & $\begin{array}{l}\text {-real time } \\
\text {-high accuracy }\end{array}$ & $\begin{array}{l}\text { - high computation } \\
\text { overhead } \\
\text { - high FPR }\end{array}$ & $\begin{array}{l}\text { Tensor flow } \\
\text { and Keras in } \\
\text { Python }\end{array}$ & $\begin{array}{l}\text { John } \\
\text { Radcliffe } \\
\text { Hospital data }\end{array}$ \\
\hline $\begin{array}{l}\text { (Rathore et al. } \\
\text { 2018) }\end{array}$ & $\begin{array}{l}\text { neural } \\
\text { network- } \\
\text { based MLP }\end{array}$ & $\begin{array}{l}\text { Anomaly based false } \\
\text { alarm detection }\end{array}$ & $\begin{array}{l}\text {-real time } \\
\text {-energy efficient } \\
\text {-high accuracy } \\
\text {-reliable }\end{array}$ & $\begin{array}{l}\text { - high memory } \\
\text { requirement due to } \\
\text { training overhead }\end{array}$ & $\begin{array}{l}\text { NI myRIO } \\
\text { FPGA-based } \\
\text { MLP }\end{array}$ & $\begin{array}{l}\text { UCI } \\
\text { Diabetic } \\
\text { dataset }\end{array}$ \\
\hline $\begin{array}{l}\text { (Khan et al. } \\
\text { 2017) }\end{array}$ & $\begin{array}{l}\text { DWT and } \\
\text { Marcov } \\
\text { model }\end{array}$ & $\begin{array}{l}\text { Anomaly based false } \\
\text { data detection }\end{array}$ & $\begin{array}{l}\text {-high detection rate } \\
\text {-high TNR } \\
\text {-real time }\end{array}$ & $\begin{array}{l}\text { - detection rate decreases } \\
\text { when there is too much } \\
\text { attack } \\
\text { - high FNR and FPR }\end{array}$ & MATLAB & $\begin{array}{l}\text { The ECG } \\
\text { dataset from } \\
\text { MIT- } \\
\text { PHYSIOBAN } \\
\text { K }\end{array}$ \\
\hline $\begin{array}{l}\text { (Gao and } \\
\text { Thamilarasu } \\
\text { 2017) }\end{array}$ & $\begin{array}{l}\text { Decision } \\
\text { tree, SVM } \\
\text { and K- } \\
\text { means }\end{array}$ & $\begin{array}{l}\text { Anomaly-based attack } \\
\text { detection }\end{array}$ & $\begin{array}{l}\text { - high accuracy } \\
\text { - low FPR } \\
\text { - low training time } \\
\text { - low prediction time }\end{array}$ & $\begin{array}{l}\text { - no validation } \\
\text { - memory, battery usage is } \\
\text { not considered } \\
\text { - fails in detecting insider } \\
\text { attack }\end{array}$ & Castalia & $\begin{array}{l}\text { Simulation } \\
\text { data }\end{array}$ \\
\hline $\begin{array}{l}\text { (Sehatbakhsh et } \\
\text { al. 2018) }\end{array}$ & $\begin{array}{l}\text { (K-S test) } \\
\text { on external } \\
\text { hardware } \\
\text { device }\end{array}$ & $\begin{array}{l}\text { malware Anomaly } \\
\text { detection }\end{array}$ & $\begin{array}{l}\text {-high TPR } \\
\text {-low FPR } \\
\text {-low detection latency } \\
\text {-no overhead on the } \\
\text { medical device }\end{array}$ & $\begin{array}{l}\text { - external device needs } \\
\text { maintenance and the } \\
\text { device itself could be } \\
\text { hacked (stolen or lost) }\end{array}$ & $\begin{array}{l}\text { Open Syringe } \\
\text { Pump } \\
\text { Arduino UNO, } \\
\text { Nios-II, } \\
\text { OlimexA13, } \\
\text { and TS-7250 }\end{array}$ & Testbed data \\
\hline $\begin{array}{l}\text { (Zhang, } \\
\text { Raghunathan and } \\
\text { Jha 2013) }\end{array}$ & $\begin{array}{l}\text { a model is } \\
\text { embedded } \\
\text { on an } \\
\text { external } \\
\text { device }\end{array}$ & $\begin{array}{l}\text { multi-layered anomaly } \\
\text { detection. }\end{array}$ & $\begin{array}{l}\text { - zero overhead on } \\
\text { battery } \\
\text { - real time } \\
\text { - multiple attacks } \\
\text { detection } \\
\text { - hybrid detection }\end{array}$ & $\begin{array}{l}\text {-protecting only integrity } \\
\text { - external device needs } \\
\text { maintenance and it could } \\
\text { be hacked (stolen or lost) } \\
\text { - lack of behavioral } \\
\text { anomaly detection } \\
\text { experiment }\end{array}$ & $\begin{array}{l}\text { USRP } \\
\text { Glucose } \\
\text { monitoring } \\
\text { and insulin } \\
\text { delivery } \\
\text { systems }\end{array}$ & Testbed data \\
\hline $\begin{array}{l}\text { (Newaz et al. } \\
\text { 2019) }\end{array}$ & $\begin{array}{l}\text { ANN, DT, } \\
\text { RF, and k- } \\
\text { NN }\end{array}$ & $\begin{array}{l}\text { Anomaly detection } \\
\text { Uses medical device } \\
\text { data }\end{array}$ & $\begin{array}{l}\text {-high accuracy } \\
\text {-high F1 } \\
\text {-No overhead on the } \\
\text { sensors } \\
\text { - uses body } \\
\text { functioning data } \\
\end{array}$ & $\begin{array}{l}\text { - high training overhead } \\
\text { - performance overhead } \\
\text { not calculated. }\end{array}$ & MATLAB & $\begin{array}{l}\text { A set of heath } \\
\text { dataset from } \\
\text { different } \\
\text { sources }\end{array}$ \\
\hline $\begin{array}{l}\text { (Ben Amor, } \\
\text { Lahyani and } \\
\text { Jmaiel 2020) }\end{array}$ & $\begin{array}{l}\text { PCA and } \\
\text { Correlation } \\
\text { Coefficient }\end{array}$ & $\begin{array}{l}\text { Anomaly based faulty } \\
\text { sensor data detection. }\end{array}$ & $\begin{array}{l}\text { - real time } \\
\text { - lightweight } \\
\text { - improved accuracy } \\
\text { - improved FPR }\end{array}$ & $\begin{array}{l}\text {-energy, CPU usage is not } \\
\text { considered } \\
\text {-lacks attack detection at } \\
\text { server and transmission }\end{array}$ & $\begin{array}{l}\text { AUDITmodul } \\
\text { e } \\
\text { Java and R } \\
\text { languages }\end{array}$ & $\begin{array}{l}\text { MIMIC } \\
\text { database }\end{array}$ \\
\hline $\begin{array}{l}\text { (Mohamed, } \\
\text { Meddeb- } \\
\text { Makhlouf and } \\
\text { Fakhfakh 2019) }\end{array}$ & $\begin{array}{l}\text { Statistical } \\
\text { signal } \\
\text { amplitude } \\
\text { calculation }\end{array}$ & $\begin{array}{l}\text { Anomaly based } \\
\text { intrusion cancellation }\end{array}$ & $\begin{array}{l}\text { - using more than one } \\
\text { type of Sensor type } \\
\text { - high TPR }\end{array}$ & $\begin{array}{l}\text { - not lightweight } \\
\text {-not real time } \\
\text {-high performance } \\
\text { overhead }\end{array}$ & MATLAB & $\begin{array}{l}\text { real } \\
\text { medical ECG } \\
\text { and EMG } \\
\text { datasets }\end{array}$ \\
\hline $\begin{array}{l}\text { (Salem et al. } \\
2014)\end{array}$ & $\begin{array}{l}\text { Classifiers } \\
\text { (SVM, RF, } \\
\text { K-NN, } \\
\text { Decision } \\
\text { Trees) and } \\
\text { Regression } \\
\end{array}$ & $\begin{array}{l}\text { Anomaly detection for } \\
\text { sensor physiological } \\
\text { data }\end{array}$ & $\begin{array}{l}\text { - low detection time } \\
\text { - high TPR } \\
\text { - low FNR }\end{array}$ & $\begin{array}{l}\text {-not lightweight } \\
\text {-performance overhead not } \\
\text { calculated }\end{array}$ & Weka & $\begin{array}{l}\text { MIMIC } \\
\text { dataset }\end{array}$ \\
\hline (Hau and Lupu & Time series & Anomaly based false & -High detection for & -long detection time & Not given & MIMIC \\
\hline
\end{tabular}




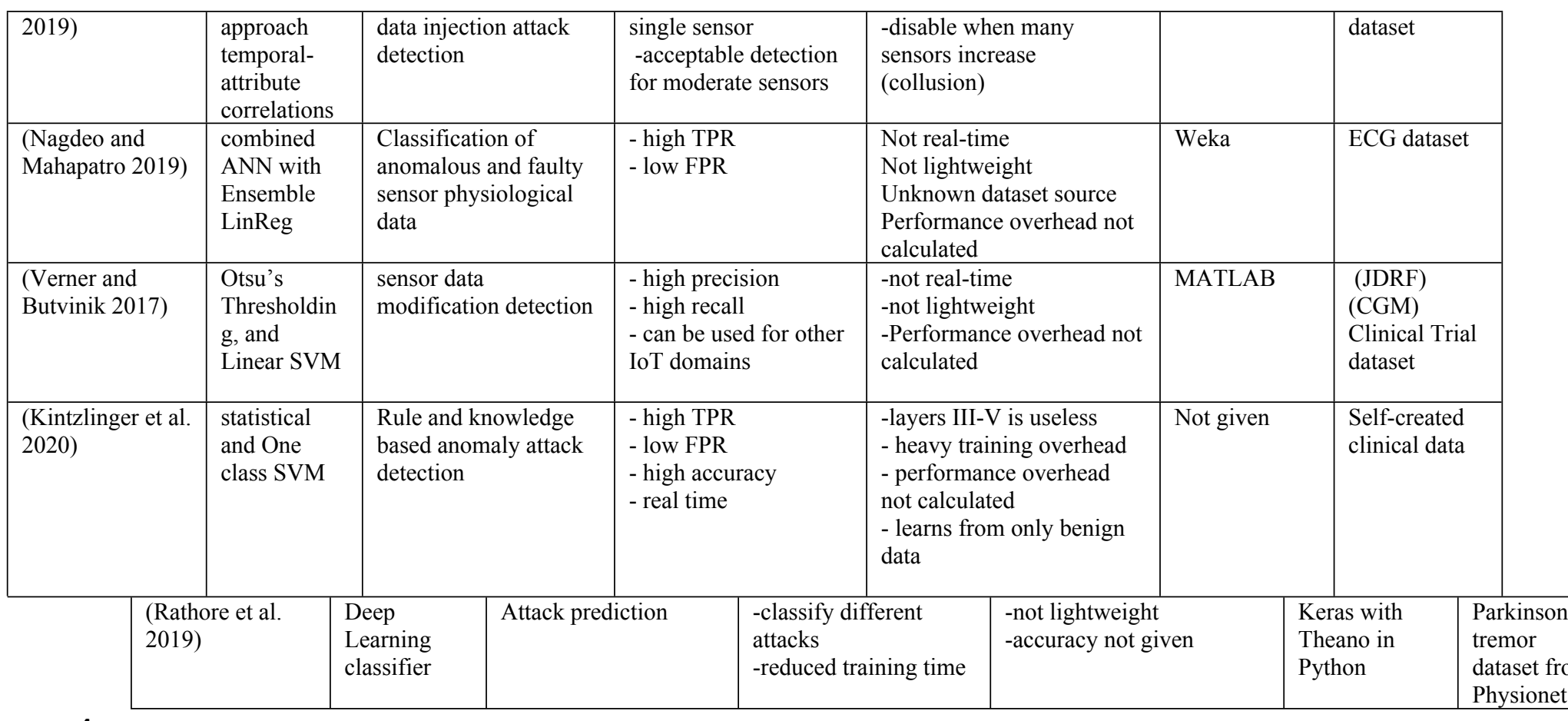




\section{Table 9 (on next page)}

Table 9: The summary of the studies reported on authentication and access control.

each row represent each paper under category authentication and access control and the columns show their characteristics that are used for evaluating them 
1 Table 9:

2 The summary of the studies reported on authentication and access control.

\begin{tabular}{|c|c|c|c|c|c|}
\hline Ref. & Methods & Good Features & Gaps and limitation & tools & Data info \\
\hline $\begin{array}{l}\text { (Rathore et al. } \\
\text { 2018b) }\end{array}$ & $\begin{array}{l}\text { Legendre } \\
\text { approximation } \\
\text { and MLP }\end{array}$ & $\begin{array}{l}\text {-High testing } \\
\text { accuracy }\end{array}$ & $\begin{array}{l}\text {-High computational overhead for IMD. } \\
\text {-Not able to detect unknown attacks. }\end{array}$ & $\begin{array}{l}\text { MATLAB } \\
\text { Keras } \\
\text { Theano }\end{array}$ & ECG-ID dataset \\
\hline $\begin{array}{l}\text { (Pirbhulal et } \\
\text { al. 2019) }\end{array}$ & MLP & $\begin{array}{l}\text {-Efficient } \\
\text {-Light weight }\end{array}$ & $\begin{array}{l}\text {-Evaluation not given. } \\
\text {-Lacks validation metrics. } \\
\text {-MLP is memory intensive. }\end{array}$ & Not given & Not given \\
\hline $\begin{array}{l}\text { (Mawgoud et } \\
\text { al. 2019) }\end{array}$ & $\begin{array}{l}\text { SVM and trust } \\
\text { management }\end{array}$ & $\begin{array}{l}\text {-Low resource } \\
\text { consumption } \\
\text {-Lower detection } \\
\text { time }\end{array}$ & $\begin{array}{l}\text {-Performance overhead not calculated. } \\
\text {-Lacks measuring the cryptography security } \\
\text { strength of the algorithm. }\end{array}$ & Not given & Not available \\
\hline $\begin{array}{l}\text { (Barros et al. } \\
\text { 2019) }\end{array}$ & $\begin{array}{l}\text { MLP, RF, } \\
\text { SVM and } \\
\text { Naïve bayes }\end{array}$ & $\begin{array}{l}\text {-Low complexity } \\
\text {-High accuracy }\end{array}$ & $\begin{array}{l}\text { - Performance overhead not calculated } \\
\text {-High Training overhead } \\
\text {-Reduced accuracy due to feature selection } \\
\text {-Not easy to implement with different sensors }\end{array}$ & Weka & $\begin{array}{l}\text { Stress } \\
\text { Recognition in } \\
\text { Automobile } \\
\text { Drivers } \\
\text { database } \\
\end{array}$ \\
\hline $\begin{array}{l}\text { (Zhang et al. } \\
\text { 2018) }\end{array}$ & $\begin{array}{l}\text { 2DPCA, LDA, } \\
\text { and } \\
\text { MapReduce }\end{array}$ & $\begin{array}{l}\text {-Improved accuracy } \\
\text {-Improved } \\
\text { efficiency }\end{array}$ & $\begin{array}{l}\text {-Performance overhead not calculated. } \\
\text {-High training overhead } \\
\text { - Not suitable for tiny IoT devices }\end{array}$ & Hadoop & $\begin{array}{l}\text { MIT-BIH } \\
\text { Database }\end{array}$ \\
\hline $\begin{array}{l}\text { (Shang \& Wu } \\
\text { 2019) }\end{array}$ & LOF model & $\begin{array}{l}\text {-Improved accuracy } \\
\text { in acceptance and } \\
\text { rejection }\end{array}$ & $\begin{array}{l}\text {-Not accurate when user's behavior not stable. } \\
\text {-Different performance on different brands of } \\
\text { smartwatch } \\
\text {-Sensors should be attached to body tightly. } \\
\text {-Performance overhead not calculated }\end{array}$ & $\begin{array}{l}\text { Samsung } \\
\text { smartwatchTi } \\
\text { zen OS } 3.0\end{array}$ & Self-created \\
\hline $\begin{array}{l}\text { (Musale et al. } \\
\text { 2019) }\end{array}$ & $\begin{array}{l}\text { Statistical } \\
\text { filers, RF, } \\
\text { KNN, } \\
\text { and MLP }\end{array}$ & $\begin{array}{l}\text {-Lightweight } \\
\text {-Higher accuracy } \\
\text {-User-friendly } \\
\text {-Easily deployable }\end{array}$ & $\begin{array}{l}\text { - performance overhead not calculated. } \\
\text { - No attack model is considered for gait } \\
\text { authentication. } \\
\text { - Environment can affect its accuracy. } \\
\text { - Authentication fails if the user is far from } \\
\text { smart home. } \\
\text { - Its accuracy decreases in the case of } \\
\text { increasing the users }\end{array}$ & $\begin{array}{l}\text { Motorola } \\
\text { (smartphone) } \\
\text { python }\end{array}$ & Self-created \\
\hline $\begin{array}{l}\text { (Vhaduri \& } \\
\text { Poellabauer } \\
\text { 2019) }\end{array}$ & $\begin{array}{l}\text { A combination } \\
\text { of filters } \\
\text { ((KS)-test, PC, } \\
\text { SD based } \\
\text { filter ) and } \\
\text { SVM }\end{array}$ & $\begin{array}{l}\text {-Use of hybrid } \\
\text { biometric. } \\
\text {-High accuracy } \\
\text {-Low error rate }\end{array}$ & $\begin{array}{l}\text {-Degradation of Non-Sedentary performance } \\
\text { for highly active periods. } \\
\text {-Need for retraining. } \\
\text {-Cannot detect online attacks } \\
\text {-performance overhead not calculated. }\end{array}$ & MATLAB & $\begin{array}{l}\text { NetHealth } \\
\text { Study Dataset }\end{array}$ \\
\hline $\begin{array}{l}\text { (Mohsen et al. } \\
\text { 2019) }\end{array}$ & $\begin{array}{l}\text { Cryptography, } \\
\text { convolutional } \\
\text { Neural } \\
\text { network } \\
(\mathrm{CNN})\end{array}$ & $\begin{array}{l}\text {-End to end security } \\
\text {-Strong against } \\
\text { multiple attacks } \\
\text {-Lightweight } \\
\text { - Real time }\end{array}$ & $\begin{array}{l}\text {-Communication overhead is still high for } \\
\text { medical devices. } \\
\text {-High training overhead. } \\
\text { - Performance overhead not calculated. } \\
\text {-Some attacks may still occur in that } 30 \text { min of } \\
\text { monitoring gap ex; sensor may be relocated and } \\
\text { returned }\end{array}$ & Not available & Not available \\
\hline $\begin{array}{l}\text { (Punithavathi } \\
\text { et al. 2019) }\end{array}$ & $\begin{array}{l}\text { a lightweight } \\
\text { random } \\
\text { projection } \\
\text { technique }\end{array}$ & $\begin{array}{l}\text {-Low complexity } \\
\text {-Lightweight } \\
\text {-High recognition } \\
\text { accuracy }\end{array}$ & $\begin{array}{l}\text {-Rejection rate not calculated. } \\
\text {-memory, energy usage is not calculated. } \\
\text {-Missing attack validation }\end{array}$ & $\begin{array}{l}\text { OpenCV } 3.6 \\
\text { in Python 3.4. }\end{array}$ & $\begin{array}{l}\text { DB1 and DB2 } \\
\text { of FVC2002 } \\
\text { and FVC2004 }\end{array}$ \\
\hline $\begin{array}{l}\text { (Rathore et al. } \\
\text { 2018a) }\end{array}$ & $\begin{array}{l}\text { Dynamic } \\
\text { Time Warping } \\
\text { (DTW) }\end{array}$ & $\begin{array}{l}\text {-Lightweight } \\
\text {-Efficient } \\
\text {-High accuracy } \\
\text {-Less complex }\end{array}$ & $\begin{array}{l}\text {-Missing validation against attacks } \\
\text {-Acceptance and Rejection rate not calculated. } \\
\text {-Heavy for implantable devices }\end{array}$ & $\begin{array}{l}\text { LabVIEW } \\
\text { MathScript } \\
\text { RT Module }\end{array}$ & ECG-ID dataset \\
\hline $\begin{array}{l}\text { (Mohsin et al. } \\
\text { 2019) }\end{array}$ & $\begin{array}{l}\text { PSO, } \\
\text { Blockchain, } \\
\text { AES }\end{array}$ & $\begin{array}{l}\text {-Higher secure } \\
\text { transmission } \\
\text {-Strong against } \\
\text { spoofing and brute- }\end{array}$ & $\begin{array}{l}\text {-Key distribution in AES adds extra load on the } \\
\text { channels. } \\
\text {-Block chain is a heavy and resource extensive }\end{array}$ & Not given & $\begin{array}{l}\text { MMCBNU_600 } \\
0 \text { database }\end{array}$ \\
\hline
\end{tabular}




\begin{tabular}{|l|l|l|l|l|l|}
\hline & & $\begin{array}{l}\text { force attacks } \\
\text {-High accuracy }\end{array}$ & & & \\
\hline
\end{tabular}




\section{Table $\mathbf{1 0}$ (on next page)}

Table 10: Summary of the studies reported on intrusion and malware detection.

each row represent each paper under category intrusion and malware detection, the columns show their characteristics that are used for evaluating them 
2 Table 10:

3 Summary of the studies reported on intrusion and malware detection.

\begin{tabular}{|c|c|c|c|c|c|c|}
\hline Ref. & Method & $\begin{array}{l}\text { Type of Intrusion } \\
\text { detection }\end{array}$ & Good features & Gaps and Limitations & $\begin{array}{l}\text { Tools } \\
\text { (softwared } \\
\text { hardware) }\end{array}$ & Datasets \\
\hline $\begin{array}{l}\text { (Begli, } \\
\text { Derakhshan and } \\
\text { Karimipour } \\
\text { 2019) }\end{array}$ & SVM & $\begin{array}{l}\text { Anomaly and } \\
\text { signature-based } \\
\text { IDS }\end{array}$ & $\begin{array}{l}\text {-High detection } \\
\text { accuracy } \\
\text {-Satisfied detection } \\
\text { time }\end{array}$ & $\begin{array}{l}\text { - High memory } \\
\text { overhead } \\
\text { - Low detection rate in } \\
\text { misuse analysis } \\
\text {-Outdated dataset }\end{array}$ & R program & NSL-KDD \\
\hline $\begin{array}{l}\text { (Itten and } \\
\text { Vadakkumcheril } \\
\text { 2016) }\end{array}$ & $\begin{array}{l}\text { a multivariate } \\
\text { correlation analysis }\end{array}$ & $\begin{array}{l}\text { Hybrid Anomaly } \\
\text { and rule based } \\
\text { IDS }\end{array}$ & $\begin{array}{l}\text { - Improved } \\
\text { accuracy. } \\
\text { - Detecting known } \\
\text { and unknown } \\
\text { attacks. }\end{array}$ & $\begin{array}{l}\text { - High learning } \\
\text { overhead } \\
\text { - Unclear } \\
\text { implementation } \\
\text { - Validation process } \\
\text { not given }\end{array}$ & Not given & Not given \\
\hline $\begin{array}{l}\text { (Schneble and } \\
\text { Thamilarasu } \\
\text { 2019) }\end{array}$ & Federated Learning & $\begin{array}{l}\text { Anomaly based } \\
\text { false data } \\
\text { injection, data } \\
\text { modification, DoS } \\
\text { IDS }\end{array}$ & $\begin{array}{l}\text {-Multiple attack } \\
\text { detection } \\
\text {-High accuracy } \\
\text { - Low FPR } \\
\text { - Flexible }\end{array}$ & $\begin{array}{l}\text { - Reduced accuracy } \\
\text { and increased FPR in } \\
\text { some cases } \\
\text { - Weak against } \\
\text { adversarial attacks }\end{array}$ & $\begin{array}{l}\text { - Sci-kit } \\
\text { Learn's on } \\
\text { Raspberry } \\
\text { Pi's. } \\
\text { - MATLAB }\end{array}$ & $\begin{array}{l}\text { - MIMIC dataset } \\
\text { from PhysioNet } \\
\text { - ECG }\end{array}$ \\
\hline $\begin{array}{l}\text { (Odesile and } \\
\text { Thamilarasu } \\
\text { 2017) }\end{array}$ & $\begin{array}{l}\text { Hierarchical and } \\
\text { distributed classifiers } \\
\text { (NBC, KNN, SVM, } \\
\text { RF and DT) }\end{array}$ & $\begin{array}{l}\text { Anomaly based } \\
\text { IDS }\end{array}$ & $\begin{array}{l}\text { - High accuracy } \\
\text { - Low energy } \\
\text { consumption }\end{array}$ & $\begin{array}{l}\text { - High training time } \\
\text { for some methods } \\
\text { - High FPR }\end{array}$ & $\begin{array}{l}\text { Castalia } \\
\text { WBAN }\end{array}$ & $\begin{array}{l}\text { Self-created } \\
\text { simulated data }\end{array}$ \\
\hline $\begin{array}{l}\text { (Schneble and } \\
\text { Thamilarasu } \\
\text { 2019) }\end{array}$ & $\begin{array}{l}\text { feature selection } \\
\text { (Laplacian scoring) }\end{array}$ & $\begin{array}{l}\text { Signature based } \\
\text { intrusion } \\
\text { detection. }\end{array}$ & $\begin{array}{l}\text { - Reduced the } \\
\text { detection time. } \\
\text { - Reduced } \\
\text { performance } \\
\text { overhead }\end{array}$ & $\begin{array}{l}\text { - Accuracy reduced } \\
\text { upon selecting more } \\
\text { features. } \\
\text { - Lacks detail of } \\
\text { selected features. }\end{array}$ & Not given & $\begin{array}{l}\text { MIT-BIH } \\
\text { Arrhythmia } \\
\text { dataset }\end{array}$ \\
\hline (He et al. 2019) & $\begin{array}{l}\text { SAE is used for } \\
\text { feature selection }\end{array}$ & $\begin{array}{l}\text { Signature based } \\
\text { intrusion } \\
\text { detection. } \\
\text { HIDS }\end{array}$ & $\begin{array}{l}\text { - Improved } \\
\text { accuracy and } \\
\text { detection overhead }\end{array}$ & $\begin{array}{l}\text { - High training } \\
\text { overhead } \\
\text { - Not lightweight }\end{array}$ & Not given & $\begin{array}{l}\text { real CHS Source } \\
\text { not given }\end{array}$ \\
\hline (RM et al. 2020) & $\begin{array}{l}\text { Feature selection } \\
\text { using PCA and } \\
\text { GWO with DL } \\
\text { classifier }\end{array}$ & $\begin{array}{l}\text { Signature based } \\
\text { IDS } \\
\text { NIDS }\end{array}$ & $\begin{array}{l}\text {-high accuracy } \\
\text { low training and } \\
\text { testing time }\end{array}$ & $\begin{array}{l}\text { - High Memory and } \\
\text { CPU overhead. } \\
\text { - Limited to only IP } \\
\text { based devices. }\end{array}$ & Not given & NSL-KDD \\
\hline $\begin{array}{l}\text { (Thamilarasu } \\
\text { 2016) }\end{array}$ & $\begin{array}{l}\text { multi-objective } \\
\text { genetic algorithm } \\
\text { (GA) }\end{array}$ & $\begin{array}{l}\text {-Signature based } \\
\text { IDS } \\
\text {-HIDS }\end{array}$ & $\begin{array}{l}\text {-F selection } \\
\text { reduced the } \\
\text { complexity }\end{array}$ & $\begin{array}{l}\text { - Not lightweight } \\
\text { - Detection time and } \\
\text { training time not given. }\end{array}$ & MATLAB & $\begin{array}{l}\text { Self-created by } \\
\text { simulation }\end{array}$ \\
\hline $\begin{array}{l}\text { (Asfaw et al. } \\
\text { 2010) }\end{array}$ & $\begin{array}{l}\text { Data mining-based } \\
\text { Association rule } \\
\text { mining }\end{array}$ & $\begin{array}{l}\text {-Anomaly based } \\
\text { HIDS }\end{array}$ & $\begin{array}{l}\text {-Ability to detect } \\
\text { anomalous } \\
\text { activity. }\end{array}$ & $\begin{array}{l}\text { - Lacks model } \\
\text { evaluation } \\
\text { - Using many } \\
\text { resources }\end{array}$ & $\begin{array}{l}\text {-J2ME } \\
\text {-Java Servlets } \\
\text {-MySQL } \\
\text { Server } \\
\text {-Palm PDA }\end{array}$ & Self-created \\
\hline $\begin{array}{l}\text { (Manimurugan } \\
\text { et al. 2020) }\end{array}$ & $\begin{array}{l}\text { Deep Belief Network } \\
(\mathrm{DBN})\end{array}$ & $\begin{array}{l}\text {-Anomaly based } \\
\text { NIDS. }\end{array}$ & $\begin{array}{l}\text {-High accuracy } \\
\text {-High precision, } \\
\text { F1, and recall. }\end{array}$ & $\begin{array}{l}\text { - FPR and performance } \\
\text { overhead neglected. } \\
\text { - -High training } \\
\text { overhead }\end{array}$ & MATLAB & $\begin{array}{l}\text { CICIDS2017 } \\
\text { dataset }\end{array}$ \\
\hline
\end{tabular}




\begin{tabular}{|c|c|c|c|c|c|c|}
\hline $\begin{array}{l}\text { (Alrashdi et al. } \\
\text { 2019) }\end{array}$ & $\begin{array}{l}\text { Ensemble } \\
\text { an online sequential } \\
\text { extreme learning } \\
\text { machine (EOS- } \\
\text { ELM) }\end{array}$ & $\begin{array}{l}\text {-Anomaly based } \\
\text { NIDS. }\end{array}$ & $\begin{array}{l}\text { - Lower latency } \\
\text { compared with } \\
\text { cloud-based. } \\
\text { - Reduced attack } \\
\text { detection time }\end{array}$ & $\begin{array}{l}\text {-Memory and CPU } \\
\text { usage are not } \\
\text { considered }\end{array}$ & $\begin{array}{l}\text {-Python } \\
\text { (scikit-learn, } \\
\text { Tensorflow, } \\
\text { Keras, } \\
\text { Numpy, } \\
\text { HDF5) } \\
\end{array}$ & $\begin{array}{l}\text { NSL-KDD } \\
\text { dataset }\end{array}$ \\
\hline $\begin{array}{l}\text { (Wazid et al. } \\
\text { 2019) }\end{array}$ & $\begin{array}{l}\text { Machine Learning, } \\
\text { Data mining, } \\
\text { Blockchain }\end{array}$ & $\begin{array}{l}\text {-Signature and } \\
\text { Anomaly based } \\
\text { Malware } \\
\text { detection. }\end{array}$ & $\begin{array}{l}\text { Discussed current } \\
\text { IoMT malware } \\
\text { detection }\end{array}$ & $\begin{array}{l}\text { Most papers are } \\
\text { generic IoT especially } \\
\text { Smart phone-based } \\
\text { solutions. }\end{array}$ & Not given & Not given \\
\hline $\begin{array}{l}\text { (Fernandez } \\
\text { Maimo et al. } \\
\text { 2019) }\end{array}$ & $\begin{array}{l}\text { NFV / SDN, OC- } \\
\text { SVM , and Naïve } \\
\text { Bayes }\end{array}$ & $\begin{array}{l}\text {-Anomaly and } \\
\text { signature-based } \\
\text { Ransomware } \\
\text { detection. }\end{array}$ & $\begin{array}{l}\text { - Real time } \\
\text { - Can detect recent } \\
\text { malware attacks. } \\
\text { - Short detection } \\
\text { time }\end{array}$ & $\begin{array}{l}\text { - Not lightweight } \\
\text { - performance } \\
\text { overhead not } \\
\text { calculated }\end{array}$ & $\begin{array}{l}\text { - OpenICE } \\
\text { - OpenStack } \\
\text { - } \\
\text { OpenDaylight } \\
\text { - Python } \\
\text { language } \\
\text { - Scikit-learn } \\
\text { v0.20.0 }\end{array}$ & $\begin{array}{c}\text { Self-created real } \\
\text { testbed } \\
\text { dataset }\end{array}$ \\
\hline $\begin{array}{l}\text { (Shakeel et al. } \\
2018 \text { ) }\end{array}$ & $\begin{array}{l}\text { Deep-Q-Network } \\
\text { (LDQN) }\end{array}$ & $\begin{array}{l}\text {-Signature based } \\
\text { malware } \\
\text { detection. }\end{array}$ & $\begin{array}{l}\text { - High detection } \\
\text { rate } \\
\text { - Low error } \\
\text { - Low energy } \\
\text { consumption }\end{array}$ & $\begin{array}{l}\text { - FPR, Memory usage } \\
\text { are not considered. } \\
\text { - Training overhead is } \\
\text { high }\end{array}$ & $\begin{array}{l}\text { NS2 } \\
\text { simulator }\end{array}$ & Simulated data \\
\hline $\begin{array}{l}\text { (Landau et al. } \\
2020 \text { ) }\end{array}$ & $\begin{array}{l}\text { Different ML } \\
\text { techniques }\end{array}$ & $\begin{array}{l}\text {-Privacy attack } \\
\text { detection. }\end{array}$ & $\begin{array}{l}\text {-Improved } \\
\text { performance } \\
\text {-Larger datasets } \\
\text { used }\end{array}$ & $\begin{array}{l}\text { - Still low accuracy } \\
\text { - high error rare }\end{array}$ & Not given & rsEEG data \\
\hline
\end{tabular}

4 